\title{
Construction of a Convenient Screening Method for $P$ - Hydroxybenzoate Hydroxylase To Enable Efficient Gallic Acid and Pyrogallol Biosynthesis
}

\section{Zhenya Chen}

Beijing Institute of Technology

\section{Tongtong Chen}

Beijing Institute of Technology

\section{Shengzhu Yu}

Beijing Institute of Technology

Yi-Xin Huo ( $\square$ huoyixin@bit.edu.cn )

College of Life Science, Beijing Institute of Technology No.5South Zhongguancun Street Beijing, China, 100081 https://orcid.org/0000-0003-4644-999X

\section{Research}

Keywords: p-hydroxybenzoate hydroxylase, screening, hydroxylation, gallic acid, pyrogallol, biosynthesis

Posted Date: November 1st, 2021

DOl: https://doi.org/10.21203/rs.3.rs-1019346/v1

License: (9) (1) This work is licensed under a Creative Commons Attribution 4.0 International License. Read Full License 


\section{Abstract}

\section{Background}

Gallic acid (GA) and pyrogallol are phenolic hydroxyl compounds and have diverse biological activities. Microbialbased biosynthesis of GA and pyrogallol has been emerged as an ecofriendly method to replace the traditional chemical synthesis. In GA and pyrogallol biosynthetic pathways, the low hydroxylation activity of $p$-hydroxybenzoate hydroxylase (PobA) towards 3,4-dihydroxybenzoic acid (3,4-DHBA) limited the high-level biosynthesis of GA and pyrogallol.

\section{Results}

This work reported a high active PobA mutant (Y385F/T294A/V349A PobA) towards 3,4-DHBA. This mutant was screened out from a PobA random mutagenesis library through a novel naked eye visual screening method. In vitro enzyme assay showed this mutant has a $k_{\text {cat }} / K_{\mathrm{m}}$ of $0.059 \mu \mathrm{M}^{-1} \mathrm{~s}^{-1}$ towards 3,4-DHBA, which was 4.92-fold higher than the reported mutant (Y385F/T294A PobA). Molecular docking simulation provided the mechanism explanation of the high activity. Expression of this mutant in E. coli BW25113 ( $\left.F^{\prime}\right)$ can generate $830 \pm 33 \mathrm{mg} / \mathrm{L} \mathrm{GA}$ from 1000 mg/L 3,4DHBA. After that, we utilized this mutant to assemble a de novo GA biosynthetic pathway. Subsequently, this pathway was introduced into a 3,4-DHBA-producing strain (E. coli BW25113 ( $\left.\mathrm{F}^{\prime}\right) \triangle \mathrm{aroE}$ ) to achieve $301 \pm 15 \mathrm{mg} / \mathrm{L}$ GA production from simple carbon sources. Similarly, assembling this mutant into a de novo pyrogallol biosynthetic pathway enabled $129 \pm 15 \mathrm{mg} / \mathrm{L}$ pyrogallol production.

\section{Conclusions}

This work established an efficient screening method and generated a high active PobA mutant. Assembling this mutant into GA and pyrogallol biosynthetic pathways achieved the de novo production of these two compounds. Besides, this mutant has great potential for GA or pyrogallol derivatives production. The screening method could be used for other GA biosynthesis-related enzymes.

\section{Background}

Gallic acid (GA) is a natural phenolic acid of plants, and its phenolic hydroxyl groups endow GA with diverse biological activities such as antioxidant, antibacterial and anti-inflammatory activities [1-7]. Pyrogallol (1,2,3-trihydroxybenzene), a decarboxylated product of GA, exhibits similar biological activities to GA $[8,9]$. Besides, pyrogallol has broadspectrum antiseptic activity $[10,11]$. According to the properties of GA and pyrogallol, these two compounds have been widely applied in food, pharmaceutical and cosmetic industries $[12,13]$. For instance, GA can recover the antioxidase activity in the liver, brain and kidney of senescence accelerated mice [14]. Pyrogallol was a crucial precursor for synthesizing antianginal drug trimethoxybenzidine [15].

Traditional method for GA production mainly relies on the hydrolysis of tannins through acids or bases [16]. In addition, GA can be alternatively produced by fermentation of tannins using the strain with active tannase [17-19]. The main approach for pyrogallol production was decarboxylation of GA via toxic chemicals under harsh conditions. Besides, enzymatic decarboxylation induced by 3,4-dihydroxybenzoic acid decarboxylase (PDC) was also utilized to produce pyrogallol [20]. The PDC-induced decarboxylation reaction required the anaerobic environment. Besides, the PDC purification was complicated and time-consuming. The abovementioned methods for GA and pyrogallol production also suffered from other drawbacks, such as the limited amount of raw materials, harsh reaction conditions, environment pollution and low yield [21]. 
In recent years, microbial-based biosynthesis has been attempted to produce many value-added compounds from simple carbon sources [22-27], including GA and pyrogallol [28, 29]. GA and pyrogallol biosynthetic pathways generally extended from 4-hydroxybenzoic acid (4-HBA), which was an Escherichia coli (E. coli) endogenous compound generated from the shikimate pathway [28]. 4-HBA can be catalyzed to form GA through a two-step reaction, which included hydroxylation of 4-HBA into 3,4-dihydroxybenzoic acid (3,4-DHBA) and hydroxylation of 3,4-DHBA into GA. This two-step reaction was generally activated by $p$-hydroxybenzoate hydroxylase (PobA). For pyrogallol biosynthesis, PDC was generally introduced into GA-producing strain in order to convert GA into pyrogallol [29]. In GA and pyrogallol biosynthetic pathways, hydroxylase PobA plays as a significant role. Native PobA from Pseudomonas fluorescens ( $P$. fluorescens) displays high hydroxylase activity towards 4-HBA, but very weak or negligible activity towards 3,4-DHBA [30]. To address this issue, previous studies mutated the tyrosine at 385th position of PobA into phenylalanine, which led PobA to hydroxylate 3,4-DHBA into GA [30,31]. Further, Chen et al. rationally designed a higher active mutant (Y385F/T294A PobA) towards 3,4-DHBA [28].

Though PobA mutants with the ability of hydroxylating 3,4-DHBA have been obtained, the hydroxylation activity was still not satisfied the demand of high-level GA and pyrogallol production. Specifically, the low activity of PobA towards 3,4-DHBA can lead carbon source to flow into the byproduct (catechol) biosynthetic pathway. Therefore, PobA mutant with higher activity urgently needs to be investigated. Rational design of PobA mutants generally required to deeply understand the catalytic mechanism of PobA. In many cases, the mutants generated from rational design did not have the expected high activity [32]. Compared to rational design, random mutagenesis is a method with higher probability to obtain high active PobA mutants. Effective screening method can ensure the acquirement of ideal mutants. In this study, we established an efficient and simple method for screening high active PobA mutants. This method depended on the instability of GA in alkaline conditions and the generated degradation products could react with each other to form a phenolic mixture [33,34]. Specifically, the mixture has a green color visible to naked eyes and the maximum absorption wavelength was at $640 \mathrm{~nm}$. Based on that, we adopted this method to screen out a PobA mutant (Y385F/T294A/V349A PobA) from a PobA random mutagenesis library. The $k_{\text {cat }}$ and $k_{\text {cat }} / K_{\mathrm{m}}$ of this mutant towards 3,4-DHBA were $1.78 \pm 0.16 \mathrm{~s}^{-1}$ and $0.059 \mu \mathrm{M}^{-1} \mathrm{~s}^{-1}$, respectively, which were 1.12- and 4.92-fold higher than that of the reported mutant (Y385F/T294A PobA), respectively. Subsequently, the in vivo conversion ability of this mutant was represented through feeding 3,4-DHBA experiments. E. coli BW25113 ( $\left.F^{\prime}\right)$ with Y385F/T294A/V349A PobA expression could convert $1000 \mathrm{mg} / \mathrm{L} 3,4-\mathrm{DHBA}$ into $830 \pm 33 \mathrm{mg} / \mathrm{L} \mathrm{GA}$, representing a 75\% molar conversion ratio. Meanwhile, $E$. coli BW25113 (F') with Y385F/T294A/V349A PobA and PDC expression could generate $323 \pm 23 \mathrm{mg} / \mathrm{L}$ pyrogallol from $1000 \mathrm{mg} / \mathrm{L}$ 3,4-DHBA. After that, we employed Y385F/T294A/V349A PobA to assemble an artificial pathway for GA production from simple carbon sources and then introduced this pathway into a 3,4-DHBA-producing strain ( $E$. coli BW25113 ( $\left.\left.F^{\prime}\right) \triangle a r o E\right)$. The de novo production of GA could reach $301 \pm 15 \mathrm{mg} / \mathrm{L}$. Correspondingly, assembling Y385F/T294A/V349A PobA into a de novo pyrogallol biosynthetic pathway could enable pyrogallol production to 129 $\pm 15 \mathrm{mg} / \mathrm{L}$. This work constructed an efficient screening method to screen out a high active PobA mutant, and this mutant has great potential for industrial GA, pyrogallol and their derived compounds production.

\section{Results And Discussion}

\section{Confirmation of GA performance in alkaline conditions}

This study aimed to acquire the PobA mutants with high hydroxylation activity towards 3,4-DHBA. As a product GA is unstable in alkaline conditions and the degradation products can react with each other to form a phenolic mixture [3337]. In this work, we firstly mixed $\mathrm{GA}$ and alkali $\mathrm{NaHCO}_{3}$. After $2 \mathrm{~h}$, we found the mixture with a pH of 9.3 displayed a green color visible to naked eyes (Fig. 1A). Moreover, the green color deepened with the increase of GA concentration. Besides, UHPLC and MS were used to analyze the mixture. Fig. S1 shows $200 \mathrm{mg} / \mathrm{L}$ GA can be completely degraded in 
2 hours. MS results in Fig. S2A show several new compounds were formed in the mixture. According to MS results, we speculated one of the new compounds might be ellagic acid (Fig. S2B), whose amount was highest in the mixture. Subsequently, the mixture was scanned at full wavelength $(340-820 \mathrm{~nm})$. Results in Fig. 1B show the mixture has a maximum absorption wavelength of $640 \mathrm{~nm}$. We then confirmed the relationship between $\mathrm{OD}_{640}$ value and GA concentration of the mixture. Fig. $1 \mathrm{C}$ shows GA concentration exhibited linear relationship with $\mathrm{OD}_{640}$ value. These results demonstrate through adding $\mathrm{NaHCO}_{3}$, the change of $\mathrm{GA}$ concentration can be observed by naked eyes, and $\mathrm{GA}$ concentration can be confirmed through detection of $\mathrm{OD}_{640}$ value. These suggest addition of $\mathrm{NaHCO}_{3}$ in the finished reaction of PobA hydroxylating 3,4-DHBA can be used as an efficient strategy for screening high active PobA mutants.

\section{Screening and in vitro enzyme assay of PobA mutants}

According to the performance of $\mathrm{GA}$ in $\mathrm{NaHCO}_{3}$, we designed a complete process for screening high active PobA mutants (Fig. 1D). Firstly, error-prone PCR was conducted on gene pobA, generating a PobA mutagenesis library. The single colonies of the library were pre-incubated into 96-deep-well plates containing LB medium, and the pre-inoculum was then transferred into another 96-deep-well plates containing M9Y medium with $1000 \mathrm{mg} / \mathrm{L}$ substrate 3,4-DHBA. After $12 \mathrm{~h}$, the culture samples were taken into 96-well plates which contained $0.1 \mathrm{M} \mathrm{NaHCO}_{3}$. After reaction for 2 hours, the samples with deepest green color were picked out, and were then re-screened through detection of $\mathrm{OD}_{640}$ value. Based on that, a high active PobA mutant (Y385F/T294A/V349A) was screened out from PobA mutagenesis library. Subsequently, this mutant was expressed and purified. SDS-PAGE in Fig. S3 shows the purity of purified Y385F/T294A/V349A PobA was greater than 95\%. Enzyme assay of the purified mutant was then performed. The nonlinear regression curves of PobA mutants towards 4-HBA and 3,4-DHBA through the Michaelis-Menten equation are shown in Fig. S4. The $K_{m}$ of Y385F/T294A/V349A PobA was 30.3 $\pm 10.4 \mu \mathrm{M}$ towards 3,4-DHBA (Table 2), which was 4.22-fold lower than that of the reported mutant (Y385F/T294A PobA), suggesting that Y385F/T294A/V349A PobA has stronger affinity towards 3,4-DHBA when compared with Y385F/T294A PobA. Besides, Y385F/T294A/V349A PobA has a $k_{\text {cat }} / K_{\mathrm{m}}$ of $0.059 \mu \mathrm{M}^{-1} \mathrm{~s}^{-1}$ towards 3,4-DHBA, a 4.92-fold higher value when compared with that of Y385F/T294A PobA. Besides, the $k_{\text {cat }} / K_{\mathrm{m}}$ of Y385F/T294A/V349A PobA towards 4-HBA was $0.094 \mu \mathrm{M}^{-1} \mathrm{~s}^{-1}$, which was 5.22-fold higher than that of Y385F/T294A PobA. These indicate Y385F/T294A/V349A PobA possesses higher catalytic efficiency towards 4-HBA or 3,4-DHBA than Y385F/T294A PobA towards 4-HBA or 3,4-DHBA.

\section{Molecular docking simulation of PobA mutants}

Subsequently, molecular docking simulation was conducted to provide mechanism explanation for the high activity of Y385F/T294A/V349A PobA. Wild-type PobA (PDB code: 1IUV) was used as template for simulation of Y385F/T294A PobA and Y385F/T294A/V349A PobA. After that, molecular docking of the mutants with substrate 3,4-DHBA and cofactor FAD were conducted. As shown in Fig. 2A and B, Y385F/T294A PobA and Y385F/T294A/V349A PobA possess similar catalytic pocket. In the pocket, amino acid residues Y201, P293 and T294A of PobA mutants, and 4$\mathrm{OH}$ of 3,4-DHBA composed a hydrogen-bond loop, which was same as the complex of wild-type PobA with native substrate 4-HBA [28]. Besides, 3-OH of 3,4-DHBA formed hydrogen bonds with P293 of PobA mutants and cofactor FAD. The hydrogen-bond loop is a stable binding. Based on that, we speculated the catalytic mechanism of PobA mutants towards 3,4-DHBA was similar to that of wild-type PobA towards 4-HBA [38, 39]. First, FAD cofactor in the complex is reduced by NADPH, which is responded to the binding of 3,4-DHBA to PobA mutants. Subsequently, the oxygen in environment oxidizes the reduced FAD to produce a hydroperoxide. The hydroperoxide then attacks the $\mathrm{C}-\mathrm{H}$ bond at $5^{\text {th }}$ position of 3,4-DHBA to generate a new hydroxyl group, forming product GA. 
Compared to Y385F/T294A PobA (Fig. 2A), a new hydrogen bond was formed between S348 and V349A in Y385F/T294A/V349A PobA (Fig. 2B), which further influenced the binding of 3,4-DHBA to Y385F/T294A/V349A PobA. As a generated result, the hydrogen bond distance between P293 of Y385F/T294A/V349A PobA and 4-OH of 3,4-DHBA

(1.9 ̊) was 1.58-fold shorter than that of Y385F/T294A PobA and 4-OH of 3,4-DHBA, suggesting the hydrogen bond between Y385F/T294A/V349A PobA and 3,4-DHBA was stronger than that between Y385F/T294A PobA and 3,4DHBA. Besides, the hydrogen bond distances between 3-OH of 3,4-DHBA and P293 of Y385F/T294A/V349A PobA and between 4-OH of 3,4-DHBA and Y201 of Y385F/T294A/V349A PobA was close to these in complex of Y385F/T294A PobA with 3,4-DHBA. These indicate the tight binding of 3,4-DHBA to Y385F/T294A/V349A PobA resulted in the high activity.

\section{Bioconversion of 3,4-DHBA into GA}

To test the in vivo conversion ability of PobA mutants towards 3,4-DHBA, Y385F/T294A PobA and Y385F/T294A/V349A PobA were individually expressed in E. coli BW25113 ( $\left.\mathrm{F}^{\prime}\right)$, generating strains CTT1 and CTT2, respectively. $1000 \mathrm{mg} / \mathrm{L}$ 3,4-DHBA was added to the culture at $5.5 \mathrm{~h}$. As shown in Fig. 3A, CTT1 accumulated $104 \pm 18$ $\mathrm{mg} / \mathrm{L} \mathrm{GA}$ at $6.5 \mathrm{~h}$, representing an initial in vivo conversion rate of $27.9 \pm 4.9 \mathrm{mg} / \mathrm{L} / \mathrm{h} / \mathrm{OD}$. The OD 600 value of CTT1 raised rapidly from $5.5 \mathrm{~h}$ to $24 \mathrm{~h}$ and reached $7.58 \pm 0.04$ at $24 \mathrm{~h}$. After this time point, the growth of CTT1 stopped. Within $24 \mathrm{~h}$, about half of $1000 \mathrm{mg} / \mathrm{L} 3,4-\mathrm{DHBA}$ was consumed and $651 \pm 5 \mathrm{mg} / \mathrm{L}$ GA was generated in the culture. In the next 24 hours, the conversion ability of CTT1 decreased and no more GA was produced. At $48 \mathrm{~h}$, GA titer reduced to $575 \pm 7 \mathrm{mg} / \mathrm{L}$ because of the degradation induced by oxidation. Meanwhile, 3,4-DHBA with a titer of $502 \pm 32 \mathrm{mg} / \mathrm{L}$ was detected, indicating that about half of $1000 \mathrm{mg} / \mathrm{L} \mathrm{3,4-DHBA}$ cannot be converted into GA by CTT1.

Similar to CTT1, $1000 \mathrm{mg} / \mathrm{L}$ 3,4-DHBA was also fed to CTT2 at $5.5 \mathrm{~h}$. The results in Fig. 3B show OD 600 value of CTT2 increased steadily throughout the 48-h feeding experiment and reached $9.07 \pm 0.14$ at $48 \mathrm{~h}$. At $6.5 \mathrm{~h}, \mathrm{CTT} 2$ produced $149 \pm 5 \mathrm{mg} / \mathrm{L} \mathrm{GA}$ in the culture and displayed an initial in vivo conversion rate of $35.4 \pm 1.2 \mathrm{mg} / \mathrm{L} / \mathrm{h} / \mathrm{OD}$, which was 1.27-fold higher than that of CTT1. Within $36 \mathrm{~h}, 1000 \mathrm{mg} / \mathrm{L} 3,4-\mathrm{DHBA}$ was completely consumed by CTT2 and $830 \pm$ $33 \mathrm{mg} / \mathrm{L}$ GA was generated, representing a 75\% molar conversion ratio. Significantly, the titer of GA was 1.27-fold higher than that of CTT1 at $24 \mathrm{~h}$. These results suggest that $E$. coli BW25113 (F') with Y385F/T294A/V349A PobA expression exhibits higher in vivo conversion ability towards 3,4-DHBA than E. coli BW25113 (F') with Y385F/T294A PobA expression.

\section{Bioconversion of 3,4-DHBA into pyrogallol}

Further, in vivo conversion of 3,4-DHBA into pyrogallol were achieved by expressing PobA mutants and decarboxylase PDC in E. coli BW25113 (F'). Plasmids PZE-PobA ${ }^{* \star}$ and pZE-PobA ${ }^{* \star \star}$ were individually introduced into E. coli BW25113 $\left(F^{\prime}\right)$ harboring pCS-PDC, resulting in strains CTT3 and CTT4, respectively. $1000 \mathrm{mg} / \mathrm{L} \mathrm{3,4-DHBA}$ was fed to CTT3 or CTT4 at $5.5 \mathrm{~h}$. As shown in Fig. 3C, CTT3 possessed a high growth rate in the first 12 hours and has an $\mathrm{OD}_{600}$ value of $6.62 \pm 0.05$ at $12 \mathrm{~h}$. Within $12 \mathrm{~h}, 9.17 \pm 5.20 \mathrm{mg} / \mathrm{L} \mathrm{GA}, 171 \pm 26 \mathrm{mg} / \mathrm{L}$ pyrogallol and $503 \pm 3 \mathrm{mg} / \mathrm{L}$ byproduct catechol accumulated in the culture. During the next 36 hours, the titer of pyrogallol increased to $222 \pm 16 \mathrm{mg} / \mathrm{L}$ at $48 \mathrm{~h}$, while the titer of catechol decreased to $465 \pm 9 \mathrm{mg} / \mathrm{L}$. Though CTT3 could convert 3,4-DHBA into pyrogallol, large accumulation of byproduct catechol was accompanied.

As a comparison, the results in Fig. 3D show CTT4 grew rapidly in the first 12 hours and has an $\mathrm{OD}_{600}$ value of $6.66 \pm$ 0.11 at $12 \mathrm{~h}$. Meanwhile, pyrogallol with a titer of $237 \pm 21 \mathrm{mg} / \mathrm{L}$ was detected in the culture, which was $1.39-\mathrm{fold}$ higher than that of CTT3 at the same time point. In addition, the byproduct catechol has a titer of $367 \pm 14 \mathrm{mg} / \mathrm{L}$, a 1.37-fold lower value when compared with that of CTT3. After $12 \mathrm{~h}, \mathrm{OD}_{600}$ value has no significant increase, which 
was similar to CTT3. Significantly, the titer of pyrogallol gradually increased to $323 \pm 23 \mathrm{mg} / \mathrm{L}$ at $48 \mathrm{~h}$, which was $1.45-$ fold higher than that of CTT3. These results indicate expressing PobA mutant and PDC in E. coli BW25113 (F') could achieve the in vivo conversion of 3,4-DHBA into pyrogallol. Moreover, Y385F/T294A/V349A PobA coupling with PDC represents higher in vivo ability of converting 3,4-DHBA into pyrogallol when compared with Y385F/T294A PobA coupling with PDC.

\section{Establishment of the biosynthetic pathway for 3,4-DHBA production}

Construction of an efficient 3,4-DHBA biosynthetic pathway was significant for achieving the de novo production of GA and pyrogallol. In previous study, 3,4-DHBA was produced from 4-HBA through expression of heterogenous PobA in $E$. coli [28]. For GA and pyrogallol production, heterogenous PobA required to catalyze two reactions, hydroxylating 4-HBA into 3,4-DHBA and hydroxylating 3,4-DHBA into GA (Fig. 4). Generally, the efficiency of two reactions induced by one kind of enzyme was lower than that of one reaction induced by one kind of enzyme. In this work, to avoid the issue of PobA-catalyzing two reactions and achieve efficient GA and pyrogallol production, E. coli BW25113 ( $F^{\prime}$ ) was engineered to produce 3,4-DHBA from 3-dehydro-shikimate (DHS) (Fig. 4). Firstly, 4-HBA biosynthetic pathway in E. coli BW25113 ( $\left.\mathrm{F}^{\prime}\right)$ was blocked through knockout of gene $\operatorname{aro} E$ (strain CTT5) or knockout of genes aroE and ydiB (strain CTT6). AroE and YdiB are isoenzymes that can catalyze DHS to produce shikimate. Fig. S5 shows CTT5 can grow in M9 medium, while CTT6 cannot grow in M9 medium because it cannot synthesize the essential amino acids phenylalanine, tyrosine and tryptophan. These results were consistent with the theoretical expectation. Subsequently, the growth curves of CTT5 and CTT6 were measured in LB medium. As shown in Fig. 5A, the OD 600 values of CTT5 and CTT6 increased with the extension of culture time. At $15 \mathrm{~h}, \mathrm{CTT} 5$ and CTT6 reached maximum $\mathrm{OD}_{600}$ values, 4.13 \pm 0.10 and $4.15 \pm 0.13$, respectively. After this time point, the growth of CTT5 and CTT6 stopped. As a comparison, the original strain E. coli BW25113 (F') has a maximum $\mathrm{OD}_{600}$ value of $4.61 \pm 0.13$ at $16 \mathrm{~h}$, which was close to that of CTT5 and CTT6 at $15 \mathrm{~h}$. After 16 h, E. coli BW25113 (F') stopped growing. These results suggest knockout of aroE or knockout of $\operatorname{aroE}$ and $y d i B$ has no significant influence on the cell growth of E. coli BW25113 (F').

To achieve the de novo production of 3,4-DHBA, 3-dehydroshikimate dehydratase (AroZ) which can catalyze 3-dehydroshikimate to produce 3,4-DHBA, was individually introduced into E. coli BW25113 (F'), CTT5 and CTT6, resulting in strains CTT7, CTT8 and CTT9, respectively. Results in Fig. 5B show 3,4-DHBA titers of CTT8 and CTT9 continued to increase during the 48-h fermentation. The growth curves of CTT8 and CTT9 were similar. The OD 600 values of CTT8 and CTT9 raised rapidly in first 12 hours and have no significant improvement during the next 36 hours. At 48 h, CTT8 produced $752 \pm 17 \mathrm{mg} / \mathrm{L} 3,4-\mathrm{DHBA}$. Meanwhile, the $\mathrm{OD}_{600}$ value was $2.03 \pm 0.06$. For CTT9, $420 \pm 26 \mathrm{mg} / \mathrm{L} 3,4-\mathrm{DHBA}$ accumulated in the culture at $48 \mathrm{~h}$, which was 1.79-fold lower than that of CTT8. These indicate the ability of strain CTT8 to produce 3,4-DHBA was higher than that of CTT9. As a comparison, CTT7 has negligible 3,4-DHBA accumulation throughout the 48-h fermentation, suggesting without knockout of aroE or $y d i B$ E. coli BW25113 ( $\left.F^{\prime}\right)$ could not synthesize 3,4-DHBA in large amount. These results suggest the engineered E. coli BW25113 (F') (CTT8 or CTT9) has ability to de novo produce 3,4-DHBA and can be used as host for de novo GA and pyrogallol production.

\section{De novo production of GA}

To achieve the de novo production of GA, plasmid pZE-AroZ-PobA** was individually introduced into E. coli BW25113 $\left(F^{\prime}\right)$, CTT5 and CTT6, generating strains CTT10, CTT11 and CTT12, respectively. The fermentation results are displayed in Fig. 6. For strain CTT10, the production of GA lasted up to $36 \mathrm{~h}$. At $36 \mathrm{~h}$, only $14.1 \pm 1.0 \mathrm{mg} / \mathrm{L} \mathrm{GA}$ accumulated in the culture, meanwhile, the $\mathrm{OD}_{600}$ value was $3.08 \pm 0.42$ (Fig. 6A). Besides, negligible 3,4-DHBA was observed in the culture, suggesting the generated 3,4-DHBA could be immediately converted into GA by strain CTT10. For strain CTT11, 3,4-DHBA and GA titers, as well as the cell growth, kept increasing throughout the 48-h fermentation (Fig. 6B). 
Significantly, within $48 \mathrm{~h}, 3,4-\mathrm{DHBA}$ with a titer of $400 \pm 17 \mathrm{mg} / \mathrm{L}$ and GA with a titer of $180 \pm 31 \mathrm{mg} / \mathrm{L}$ were detected in the culture. At the same time point, $C T T 11$ has an $\mathrm{OD}_{600}$ value of $9.10 \pm 0.51$. Notably, CTT11 produced 12.8 -fold higher amount of GA when compared with CTT10, indicating that knockout of aroE significantly increased the ability of E. coli BW25113 ( $\left.\mathrm{F}^{\prime}\right)$ to de novo produce GA. For strain CTT12, GA titer and $\mathrm{OD}_{600}$ value continued to increase during the 48-h fermentation (Fig. 6C). CTT12 has a GA titer of $46.5 \pm 8.0 \mathrm{mg} / \mathrm{L}$ and an $\mathrm{OD}_{600}$ value of $4.35 \pm 0.84$ at $48 \mathrm{~h}$. Significantly, GA titer of CTT12 was 3.87-fold lower than that of CTT11, suggesting that E. coli BW25113 $\left(\mathrm{F}^{\prime}\right) \triangle a r o E \Delta y d i B$ has lower ability to de novo synthesize GA when compared with E. coli BW25113 $\left(\mathrm{F}^{\prime}\right) \Delta a r o E$.

As a comparison, plasmid pZE-AroZ-PobA ${ }^{* \star \star}$ was individually introduced into E. coli BW25113 (F'), CTT5 and CTT6, generating strains CTT13, CTT14 and CTT15, respectively. As shown in Fig. 6D, CTT13 produced trace amount of GA $(10.9 \pm 2.3 \mathrm{mg} / \mathrm{L})$ as CTT10. For strain CTT14, the increasing trends of 3,4-DHBA and GA titers, and $\mathrm{OD}_{600}$ value were similar to that of CTT11 (Fig. 6E). Within $48 \mathrm{~h}$, the accumulation of 3,4-DHBA reached $344 \pm 11 \mathrm{mg} / \mathrm{L}$, which were 1.16fold lower than that of CTT11. Meanwhile, GA production reached $301 \pm 15 \mathrm{mg} / \mathrm{L}$, a 1.67-fold higher value when compared with that of CTT11, suggesting mutant Y385F/T294A/V349A PobA has stronger ability to de novo produce GA when compared with mutant Y385F/T294A PobA. Besides, results in Fig. 6F show strain CTT15 produced $208 \pm 20$ $\mathrm{mg} / \mathrm{L} \mathrm{3,4-DHBA}$ and $204 \pm 17 \mathrm{mg} / \mathrm{L} \mathrm{GA}$ at $48 \mathrm{~h}$, which were 1.25- and 4.39-fold higher than these of CTT12, respectively. Compared to that of CTT14, 3,4-DHBA and GA titers of CTT15 were 1.65- and 1.48-fold lower, respectively. Overall, introducing the designed artificial pathway into $E$. coli could achieve GA biosynthesis from simple carbon sources. E. coli BW25113 (F') $\triangle$ aroE demonstrates stronger ability for de novo producing $\mathrm{GA}$ when compared with $E$.

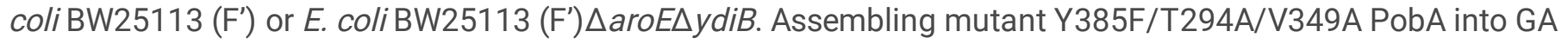
biosynthetic pathway enabled more GA production than that of assembling Y385F/T294A PobA into GA biosynthetic pathway, which were consistent with the results of in vitro enzyme assay and in vivo conversion experiments.

\section{De novo production of pyrogallol}

E. coli BW25113 (F') harboring pZE-AroZ-PobA ${ }^{* *}$ and pCS-PDC (CTT16), CTT5 harboring pZE-AroZ-PobA ${ }^{* *}$ and pCSPDC (CTT17) and CTT6 harboring pZE-AroZ-PobA* and pCS-PDC (CTT18) were constructed to de novo produce pyrogallol. The fermentation results of CTT16 in Fig. 7A show trace amount of 3,4-DHBA, GA, pyrogallol and byproduct catechol accumulated in the culture throughout the 48 -h fermentation. For $C T T 17$, the $O_{600}$ value increased during the first 24 hours and has no remarkable raise during the next 24 hours (Fig. 7B). Pyrogallol and byproduct catechol titers increased throughout the 48-h fermentation, and reached $48.6 \pm 12.0$ and $121 \pm 12 \mathrm{mg} / \mathrm{L}$ at $48 \mathrm{~h}$, respectively. At the same time point, the $\mathrm{OD}_{600}$ value was $3.02 \pm 0.21$. Besides, the accumulation of $\mathrm{GA}$ cannot be significantly detected in the culture, indicating that the generated GA was immediately converted into pyrogallol. For CTT18, pyrogallol and byproduct catechol titers raised continuously in 48 hours, and reached $19.2 \pm 5.4$ and $43.7 \pm 4.8 \mathrm{mg} / \mathrm{L}$ at $48 \mathrm{~h}$, respectively (Fig. 7C). Significantly, pyrogallol and byproduct catechol titers were 2.53- and 2.77-fold lower than these of CTT17, which suggest E. coli BW25113 ( $\left.\mathrm{F}^{\prime}\right) \triangle \operatorname{aro} E$ performed better than E. coli BW25113 ( $\left.\mathrm{F}^{\prime}\right) \Delta$ aroE $\Delta y d i B$ for de novo production of pyrogallol.

Subsequently, plasmids pZE-AroZ-PobA ${ }^{\star \star}$ and pCS-PDC were co-transferred into E. coli BW25113 (F'), CTT5 and CTT6, resulting in strains CTT19, CTT20 and CTT21, respectively. As shown Fig. 7D, CTT19 hardly produced 3,4-DHBA, GA, pyrogallol and catechol as CTT16. In Fig. 7E, CTT20 continued to grow in the first 24 hours and stopped growing in the subsequent 24 hours. CTT20 yielded $67.4 \pm 9.7 \mathrm{mg} / \mathrm{L}$ pyrogallol at $48 \mathrm{~h}$, which was 1.39 -fold higher than that of CTT17. Meanwhile, $99.7 \pm 20.3 \mathrm{mg} / \mathrm{L}$ catechol accumulated in the culture, which was 1.21 -fold lower than that of CTT17. These indicate the efficiency of mutant Y385F/T294A/V349A PobA was higher than that of mutant Y385F/T294A PobA for de novo biosynthesis of pyrogallol. For CTT21, pyrogallol was continuously synthesized in the 
first 36 hours (Fig. 7F) and has a titer of $129 \pm 15 \mathrm{mg} / \mathrm{L}$ at $36 \mathrm{~h}$, a 1.91-fold higher value when compared with that of CTT20. Meanwhile, only $6.12 \pm 0.46 \mathrm{mg} / \mathrm{L}$ catechol were detected, which was 12.0-fold lower than that of CTT20 at 36 $\mathrm{h}$. Within $48 \mathrm{~h}$, pyrogallol titer decreased to $68.5 \pm 5.0 \mathrm{mg} / \mathrm{L}$ and catechol increased to $15.8 \pm 2.6 \mathrm{mg} / \mathrm{L}$. These suggest CTT21 could achieve efficient de novo pyrogallol production, meanwhile, the accumulation of byproduct catechol was trace. In all, E. coli containing the designed artificial pathway could achieve the de novo biosynthesis of pyrogallol. Among the engineered strains, E. coli BW25113 $\left(\mathrm{F}^{\prime}\right) \triangle a r o E \Delta y d i B$ with overexpression of Y385F/T294A/V349A PobA and PDC demonstrates strongest ability for de novo production of pyrogallol.

\section{Conclusion}

The low hydroxylation activity of native PobA towards 3,4-DHBA limited the high-level production of GA and pyrogallol. Random mutagenesis was an efficient method to generate high active PobA mutants. This work first established a simple screening method which based on the instability of GA under alkaline conditions. Using this screening method

a PobA mutant (Y385F/T294A/V349A PobA) with high activity towards 3,4-DHBA was screen out from a PobA random mutagenesis library. In vitro enzyme assay demonstrates Y385F/T294A/V349A PobA possesses higher catalytic efficiency towards 4-HBA or 3,4-DHBA than Y385F/T294A PobA towards 4-HBA or 3,4-DHBA. Moreover, Y385F/T294A/V349A PobA represents higher in vivo ability of converting 3,4-DHBA into GA or pyrogallol when compared with Y385F/T294A PobA. Assembling Y385F/T294A/V349A PobA into the de novo GA or pyrogallol biosynthetic pathway achieved GA or pyrogallol production from simple carbon sources. In all, this work constructed an efficient method for screening high active hydroxylase PobA, and this method could be applied for screening other GA biosynthesis-related enzymes. The generated high active PobA has great potential for GA or pyrogallol derivatives production.

\section{Materials And Methods}

\section{Media, strains and plasmids}

Luria-Bertani (LB) medium containing $10 \mathrm{~g} \mathrm{NaCl}, 10 \mathrm{~g}$ tryptone and $5 \mathrm{~g}$ yeast extract per liter, was used for cell inoculation and propagation. For solid medium, $20 \mathrm{~g} / \mathrm{L}$ agar was added. Modified M9 (M9Y) medium which contains $11.28 \mathrm{~g} / \mathrm{L} 5 \times \mathrm{M} 9$ Minimal Salt, $10 \mathrm{~g} / \mathrm{L}$ glycerol, $2.5 \mathrm{~g} / \mathrm{L}$ glucose, $1 \mathrm{mM} \mathrm{MgSO}$, $0.05 \mathrm{mM} \mathrm{CaCl}_{2}, 2 \mathrm{~g} / \mathrm{L} \mathrm{MOPS}$ and $5 \mathrm{~g} / \mathrm{L}$ yeast extract, was used for feeding experiments and de novo production of GA and pyrogallol. Terrific Broth (TB)

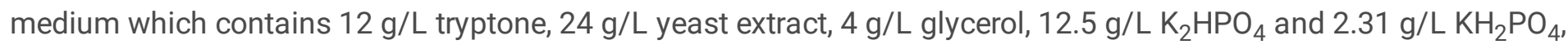
was used for protein expression. If needed, $100 \mu \mathrm{g} / \mathrm{mL}$ ampicillin, $50 \mu \mathrm{g} / \mathrm{mL}$ kanamycin or $25 \mu \mathrm{g} / \mathrm{mL}$ chloramphenicol was added to the culture. E. coli XL10-Gold and E. coli BL21(DE3) were used for plasmid construction and protein expression, respectively, while E. coli BW25113 (F') was used for feeding experiments and de novo biosynthesis of GA and pyrogallol. Plasmids pZE12-luc and pCS27 were used for pathway construction. Plasmid pETDuet-1 was used for protein expression. Plasmids pKD46 and pCP20 were used for knockout of genes. Strains and plasmids used in this study are depicted in Table 1.

\section{DNA manipulation}

Genes Y385F/T294A pobA [28] and Y385F/T294A/V349A pobA were individually cloned into pZE-luc by Gibson assembly, generating plasmids pZE-PobA ${ }^{* \star}$ and pZE-PobA ${ }^{* * *}$. Genes Y385F/T294A pobA and Y385F/T294A/V349A pobA were individually cloned into $p E T D u e t-1$, generating plasmids $p E T D$ uet-PobA ${ }^{* *}$ and $p E T D$ uet-PobA ${ }^{* *}$. To realize the efficient biosynthesis of 3,4-DHBA, gene aroZ (GenBank: VCW80955.1) was synthesized by OE-PCR, and was then inserted into pZE-luc by Gibson assembly, generating pZE-AroZ. In order to achieve GA production from simple carbon 
sources, $P_{L}$ lac01-AroZ amplified from pZE-AroZ was individually inserted into pZE-PobA ${ }^{\star \star}$ and pZE-PobA ${ }^{\star \star}$ by Gibson assembly, resulting in plasmids pZE-AroZ-PobA** and pZE-AroZ-PobA ${ }^{* \star *}$. Plasmid pCS-PDC [29] was used for conversion of GA into pyrogallol. All the plasmids were confirmed through DNA sequencing.

\section{Establishment of a PobA mutagenesis library by error-prone PCR}

To construct a PobA mutagenesis library, error-prone PCR was carried out on Y385F/T294A pobA. Plasmid pZE-pobA* was used as a template of error-prone PCR. First, 10x unbalanced dNTPs mixture which contained 2 mM dATP, 2 mM dGTP, $10 \mathrm{mM}$ dCTP and $10 \mathrm{mM}$ dTTP, was prepared. A $100 \mu \mathrm{L}$ error-prone PCR reaction mixture included $1 \mu \mathrm{L} 100 \mathrm{ng} /$ $\mu \mathrm{L}$ pZE-pobA ${ }^{* *}, 10 \mu \mathrm{L} 10 \times$ unbalanced dNTPs mixture, $0.5 \mu \mathrm{L} 25 \mathrm{mM} \mathrm{MnCl}_{2}, 1 \mu \mathrm{L} 200 \mathrm{mM} \mathrm{MgCl}_{2}, 1 \mu \mathrm{L} 10 \mu \mathrm{M}$ forward primer, $1 \mu \mathrm{L} 10 \mu \mathrm{M}$ reverse primer, $2 \mu \mathrm{L} 5 \mathrm{U} / \mu \mathrm{L}$ Hieff ${ }^{\mathrm{TM}}$ Taq DNA Polymerase, $10 \mu \mathrm{L}$ 10× M5 Taq PCR Buffer (Mg ${ }^{2+}$ free) and $73.5 \mu \mathrm{L} \mathrm{ddH_{2 }} \mathrm{O}$. The amplification program was as follows: $94^{\circ} \mathrm{C}$ initial denaturation for 3 min, and then 30 cycles of $94^{\circ} \mathrm{C}$ denaturation for $1 \mathrm{~min}, 58^{\circ} \mathrm{C}$ annealing for $1 \mathrm{~min}$ and $72^{\circ} \mathrm{C}$ extension for $1.5 \mathrm{~min}$. After that, the PCR product was confirmed and purified via agarose gel electrophoresis. The purified product was digested by $D p n$ at $37^{\circ} \mathrm{C}$ for 1.5 $\mathrm{h}$ and then cloned into pZE-luc, generating a PobA mutagenesis library.

\section{High-throughput screening of PobA mutants}

Single colonies of PobA mutagenesis library were pre-inoculated into 96-deep-well plates which contained $1 \mathrm{~mL}$ LB and $100 \mu \mathrm{g} / \mathrm{mL}$ ampicillin, and were then aerobically cultured at $37^{\circ} \mathrm{C}$ for $12 \mathrm{~h}$ to acquire the seed cultures. After that, $10 \mu \mathrm{L}$ seed cultures were transferred into $990 \mu \mathrm{L}$ M9Y medium which was supplemented with $100 \mu \mathrm{g} / \mathrm{mL}$ ampicillin ,0.5 mM isopropyl- $\beta$-D-thiogalactopyranoside (IPTG) and $1 \mathrm{~g} / \mathrm{L} \mathrm{3,4-DHBA}$ in 96-deep-well plates. The cultures were left at $30^{\circ} \mathrm{C}$ for incubation. After $12 \mathrm{~h}$, samples were taken. The samples were firstly centrifuged at $12,000 \mathrm{rpm}$ for $10 \mathrm{~min}$ to remove the cells and sediments in medium. After that, $50 \mu \mathrm{L}$ supernatant was taken into 96-well plates which contained $0.1 \mathrm{M} \mathrm{NaHCO}_{3}$. After reaction for 2 hours, the samples which with deepest green color among all the samples were screened out. The screened samples were then re-screened through detecting their optical densities at $640 \mathrm{~nm}$ with microplate reader (BioTek Cytation 3). The screened pobAs were sequenced to confirm the mutations.

\section{Expression and purification of PobA mutants}

E. coli BL21 (DE3) containing pETDuet-PobA ${ }^{\star \star}$ or pETDuet-PobA ${ }^{\star \star \star}$ was pre-inoculated in $5 \mathrm{~mL}$ LB medium which contained $100 \mu \mathrm{g} / \mathrm{mL}$ ampicillin, and was then cultured overnight at $37^{\circ} \mathrm{C}$. Then, $1 \mathrm{~mL}$ of pre-inoculum was transferred into $100 \mathrm{~mL}$ of fresh TB containing $100 \mu \mathrm{g} / \mathrm{mL}$ ampicillin and cultured at $37^{\circ} \mathrm{C}$ until $\mathrm{OD}_{600}$ reached around 0.6 . After that, $0.5 \mathrm{mM}$ IPTG was added to the culture to induce protein expression at $16^{\circ} \mathrm{C}$. After $12 \mathrm{~h}$, the cells were harvested via centrifugation (4000 rpm for $30 \mathrm{~min}$ at $4^{\circ} \mathrm{C}$ ) and then resuspended in $20 \mathrm{~mL}$ lysis buffer $(50 \mathrm{mM} \mathrm{Tris}-\mathrm{HCl}, \mathrm{pH} 7.5)$. The cells were disrupted by ultrasonic processor. The lysed mixture was centrifuged (10000 rpm for $60 \mathrm{~min}$ at $4{ }^{\circ} \mathrm{C}$ ). The supernatant was collected. The proteins were purified by nickel column. Quick Start ${ }^{\mathrm{TM}}$ Bradford Protein Assay (BIO-RED) was used for measuring protein concentrations.

\section{In vitro enzyme assay and modeling of PobA mutants}

Mutant PobAs activity was assayed by measuring the oxidation of NADPH at $340 \mathrm{~nm}$ using a microplate reader. A 500$\mu \mathrm{L}$ reaction system which contained $100 \mathrm{mM}$ Tris- $\mathrm{HCl}$ ( $\mathrm{pH}$ 8.0), $10 \mu \mathrm{M}$ FAD, $1000 \mu \mathrm{M}$ NADPH, 500 nM purified enzyme and 0-1000 $\mu \mathrm{M}$ 4-HBA or 3,4-DHBA, was used for kinetic parameters measurement. The reactions were conducted at $30{ }^{\circ} \mathrm{C}$ for $2 \mathrm{~min}$. The kinetic parameters were estimated through non-linear regression of the Michaelis-Menten equation in OriginPro8.5. 
Wild-type PobA (PDB code: 1IUV) was used as template to model the tertiary structure of PobA mutants by Swissmodel \https://swissmodel.expasy.org/). The complexes of PobA mutants with 3,4-DHBA and FAD were modeled by AutoDock (version 4.2.6). Hydrogen bonds in the complexes were analyzed by PyMOL (version 2.4).

\section{Feeding experiments}

To testify the in vivo conversion efficiency of PobA mutants towards 3,4-DHBA, feeding experiments were conducted.

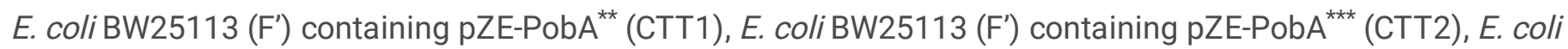
BW25113 (F') containing pZE-PobA ${ }^{* \star}$ and pCS-PDC (CTT3), and E. coli BW25113 (F') containing pZE-PobA ${ }^{\star \star *}$ and pCSPDC(CTT4) were used. The single colonies were pre-inoculated into $5 \mathrm{~mL}$ LB with $100 \mu \mathrm{g} / \mathrm{mL}$ ampicillin and then cultured at $37^{\circ} \mathrm{C}$ overnight. $200 \mu \mathrm{L}$ overnight cultures were inoculated into $20 \mathrm{~mL}$ M9Y medium containing $100 \mu \mathrm{g} / \mathrm{mL}$ ampicillin. The cultures were cultivated at $37^{\circ} \mathrm{C}$ for $2.5 \mathrm{~h}$, and then induced with $0.5 \mathrm{mM}$ IPTG at $30^{\circ} \mathrm{C}$. After induction for 3 hours, $1000 \mathrm{mg} / \mathrm{L} \mathrm{3,4-DHBA}$ was fed to the culture. For GA production, samples were taken at 5.5, 6.5, 9, 12, 24, 36 and $48 \mathrm{~h}$. For pyrogallol production, samples were taken at 12, 24, 36 and $48 \mathrm{~h}$. Cell growth was confirmed through measuring $\mathrm{OD}_{600}$. Products and intermediates were analyzed by UHPLC.

\section{Knockout of genes aroE or ydiB}

To acquire 3,4-DHBA-producing strains, gene aroE or ydiB of E. coli BW25113 ( $\left.\mathrm{F}^{\prime}\right)$ was knocked out. First, donor fragments for pre-knockout genes needed to be constructed. For knockout of gene aroE, 530 bp at the $5^{\prime}$-terminus of aroE, FRT from pRecA-FRT [40], kan, FRT and $340 \mathrm{bp}$ at the 3'-terminus of aroE were sequentially assembled through OE-PCR, generating aroE-donor. For knockout of gene $y d i B$, ydiB-donor was constructed like aroE-donor. To construct $E$. coli BW25113 (F') $\triangle$ aroE, the aroE-donor fragment was transferred into E. coli BW25113 (F') containing pKD46, and then cultured at $30{ }^{\circ} \mathrm{C}$ overnight. To eliminate pKD46, the overnight cultures were then spread on LB solid medium with $50 \mu \mathrm{g} / \mathrm{mL}$ kanamycin and then cultured at $37^{\circ} \mathrm{C}$ overnight. After that, plasmid pCP20 was transferred into the generated strain and cultured at $30^{\circ} \mathrm{C}$ overnight. To induce FLP recombinase and eliminate plasmid pCP20, the single colonies were picked and individually incubated on LB solid medium with $100 \mu \mathrm{g} / \mathrm{mL}$ ampicillin, LB solid medium with $50 \mu \mathrm{g} / \mathrm{mL}$ kanamycin and LB solid medium overnight at $43^{\circ} \mathrm{C}$. The colonies which can grow on LB solid medium and cannot grow on LB solid medium with ampicillin or kanamycin, were the colonies of strain E. coli BW25113 $\left(\mathrm{F}^{\prime}\right) \triangle a r o E$ (CTT5). The construction of E. coli BW25113 (F') $\triangle$ aroEAydiB (CTT6) was similar like CTT5.

\section{De novo production of 3,4-DHBA, GA and pyrogallol}

E. coli BW25113 ( $\mathrm{F}^{\prime}$ ) containing pZE-AroZ (CTT7), CTT5 containing pZE-AroZ (CTT8) and CTT6 containing pZE-AroZ (CTT9), were used for de novo biosynthesis of 3,4-DHBA. E. coli BW25113 (F') containing pZE-AroZ-PobA ${ }^{* *}$ (CTT10), CTT5 containing pZE-AroZ-PobA ${ }^{* *}$ (CTT11), CTT6 containing pZE-AroZ-PobA** (CTT12), E. coli BW25113 (F') containing pZE-AroZ-PobA ${ }^{* * *}$ (CTT13), CTT5 containing pZE-AroZ-PobA ${ }^{\star * \star}$ (CTT14) and CTT6 containing pZE-AroZPobA $^{\star \star \star}$ (CTT15), were used for de novo biosynthesis of GA. E. coli BW25113 (F') containing pZE-AroZ-PobA ${ }^{\star \star}$ and pCSPDC (CTT16), CTT5 containing pZE-AroZ-PobA** and pCS-PDC (CTT17), CTT6 containing pZE-AroZ-PobA ${ }^{* *}$ and pCSPDC (CTT18), E. coli BW25113 (F') containing pZE-AroZ-PobA ${ }^{\star \star \star}$ and pCS-PDC (CTT19), CTT5 containing pZE-AroZPobA $^{\star \star \star}$ and pCS-PDC (CTT20) and CTT6 containing pZE-AroZ-PobA ${ }^{\star \star}$ and pCS-PDC (CTT21), were used for de novo biosynthesis of pyrogallol. Transformants were pre-inoculated into $5 \mathrm{~mL}$ LB medium with appropriated antibiotics and cultured overnight at $37^{\circ} \mathrm{C}$. Then, $200 \mu \mathrm{L}$ seed cultures were transferred into $20 \mathrm{~mL}$ M9Y medium containing appropriated antibiotics and $0.5 \mathrm{mM} \mathrm{IPTG}$. The cultures were cultivated at $30^{\circ} \mathrm{C}$ for 48 hours. Samples were collected at $12,24,36$ and $48 \mathrm{~h} . \mathrm{OD}_{600}$ values were measured. UHPLC was used for analyzing the products and intermediates. 


\section{UHPLC analysis}

The standards (3,4-DHBA, GA, catechol and pyrogallol) were purchased from J\&K Chemicals. UHPLC (Agilent Technologies 1290 Infinity II), equipped with a reverse phase column (Agilent ZORBAX SB-C18, $5 \mu \mathrm{m}, 4.6 \times 250 \mathrm{~mm}$ ), was used for analyzing and quantifying standards and samples. Firstly, the samples were centrifuged at 12,000 rpm for 10 min to remove the cells and sediments in medium. Then, the supernatants were filtered by $0.22 \mu \mathrm{m}$ membrane and loaded. The column temperature was set at $30{ }^{\circ} \mathrm{C}$. Flowing phase containing solvent $\mathrm{A}$ (water with $0.1 \%$ formic acid) and solvent $B(100 \%$ methanol) were used, with a flow rate of $1 \mathrm{~mL} / \mathrm{min}$. The gradients were used as follows: $5 \%$ to $40 \%$ solvent B for $20 \mathrm{~min}, 100 \%$ solvent B for $2 \mathrm{~min}, 100 \%$ to $5 \%$ solvent B for $2 \mathrm{~min}$ and $5 \%$ solvent B for an additional 6 min. 3,4-DHBA, GA, catechol and pyrogallol were quantified based on their peak areas at $268 \mathrm{~nm}$.

\section{Declarations}

\section{Acknowledgements}

Not applicable.

\section{Author Contributions}

ZC and YH conceived the topic. TC performed the experiments. ZC, TC, SY and YH prepared first draft manuscript. ZC and $\mathrm{YH}$ revised the manuscript. All authors contributed to the article and approved the submitted version.

\section{Funding}

The authors would like to acknowledge financial support of the National Natural Science Foundation of China (Grant No. 21908007) and the Fundamental Research Funds for the Central Universities.

\section{Availability of data and materials}

All data generated or analyzed during this study are included in this published article and its additional files.

\section{Ethics approval and consent to participate}

Not applicable.

\section{Consent for publication}

Not applicable.

\section{Competing interests}

The authors declare that they have no competing interests.

\section{Author details}

Key Laboratory of Molecular Medicine and Biotherapy, School of Life Science, Beijing Institute of Technology, No. 5 South Zhongguancun Street, Haidian District, Beijing 100081, China

\section{References}


1. Fang Z, Zhang Y, Lue Y, Ma G, Liu JCD, Ye X. Phenolic compounds and antioxidant capacities of bayberry juices. Food Chem. 2009;113(4):884-888.

2. Ma NF, Galeano-Diaz T, Lopez O, Fernandez-Bolanos JG, Sanchez J, Miguel CD, Ma VG, Martin-Vertedor D. Phenolic compounds and antioxidant capacity of virgin olive oil. Food Chem. 2014;163:289-298.

3. Zheng W, Zhang M, Zhao Y, Miao K, Jiang H. NMR-based metabonomic analysis on effect of light on production of antioxidant phenolic compounds in submerged cultures of Inonotus obliquus. Bioresour Technol. 2009;100(19):4481-4487.

4. Aruoma OI, Murcia A, Butler J, Halliwell B. Evaluation of the antioxidant and prooxidant actions of gallic acid and its derivatives. J Agric Food Chem. 2008;41(11):1880-1885.

5. Kim, You-Jung. Antimelanogenic and antioxidant properties of gallic acid. Biol Pharm Bull. 2007;30(6):1052-1055.

6. Soong YY, Ba Rlow PJ. Quantification of gallic acid and ellagic acid from longan (Dimocarpus longan Lour.) seed and mango (Mangifera indica L.) kernel and their effects on antioxidant activity. Food Chem. 2006;97(3):524-530.

7. Yen GC, Duh PD, Tsai HL. Antioxidant and pro-oxidant properties of ascorbic acid and gallic acid. Food Chem. 2002;79(3):307-313.

8. Lima VN, Oliveira-Tintino CDM, Santos ES, Morais LP, Tintino SR, Freitas TS, Geraldo YS, Pereira RLS, Cruz RP, Menezes IRA. Antimicrobial and enhancement of the antibiotic activity by phenolic compounds: Gallic acid, caffeic acid and pyrogallol. Microb Pathog. 2016;99:56-61.

9. Xiao ZP, Ma TW, Fu WC, Peng XC, Zhu HL. The synthesis, structure and activity evaluation of pyrogallol and catechol derivatives as Helicobacter pylori urease inhibitors. Eur J Med Chem. 2010;45(11):5064-5070.

10. Taguri, Tanaka, Kouno. Antibacterial spectrum of plant polyphenols and extracts depending upon hydroxyphenyl structure. Biol Pharm Bull. 2006;29(11):2226-2235.

11. Tinh TH, Nuidate T, Vuddhakul V, Rodkhum C. Antibacterial activity of pyrogallol, a polyphenol compound against Vibrio parahaemolyticus soilated from the central region of Thailand. Procedia Chem. 2016;18:162-168.

12. Chen HM, Wu YC, Chia YC, Chang FR, Yuan SS. Gallic acid, a major component of Toona sinensis leaf extracts, contains a ROS-mediated anti-cancer activity in human prostate cancer cells. Cancer Lett. 2009;286(2):161-171.

13. Sang-Hyun K, Chang-Duk J, Kyongho S, Byung-Ju C, Hyunjeung L, Seunja P, Ho LS, Hye-Young S, Dae-Keun K, TaeYong S. Gallic acid inhibits histamine release and pro-inflammatory cytokine production in mast cells. Toxicol Sci. 2006(1):123-131.

14. Li L, Ng TB, Gao W, Li W, Fu M, Niu SM, Zhao L, Chen RR, Liu F. Antioxidant activity of gallic acid from rose flowers in senescence accelerated mice. Life Sci. 2005;77(2):230-240.

15. Rawat KA, Kailasa SK. 2,3,4-Trihydroxy benzophenone as a novel reducing agent for one-step synthesis of sizeoptimized gold nanoparticles and their application in colorimetric sensing of adenine at nanomolar concentration. RSC Adv. 2016;6:11099-11108.

16. Rommel A, Wrolstad RE. Influence of acid and base hydrolysis on the phenolic composition of red raspberry juice. J Agric Food Chem. 1993;41(8):1237-1241.

17. Beniwal V, Chhokar V, Singh N, Sharma J. Optimization of process parameters for the production of tannase and gallic acid by Enterobacter cloacae MTCC 9125. J Am Sci. 2010;6(8):389-397.

18. Kar B, Banerjee R, Bhattacharyya BC. Microbial production of gallic acid by modified solid state fermentation. J Ind Microbiol Biotechnol. 1999;23(3):173-177.

19. Trevino-Cueto, Luis, Contreras-Esquivel, JC, Rodriguez, Aguilera, Aguilar, CN. Gallic acid and tannase accumulation during fungal solid state culture of a tannin-rich desert plant (Larrea tridentata Cov.). Bioresour Technol. 2007;98(3)(-):721-724.

Page $12 / 23$ 
20. Kambourakis S, Draths KM, Frost JW. Synthesis of gallic acid and pyrogallol from glucose: replacing natural product isolation with microbial catalysis. J Am Chem Soc. 2000;122(37):8-17.

21. Rewatkar K, Shende DZ, Wasewar KL. Effect of temperature on reactive extraction of gallic acid using Tri-n-butyl Phosphate, Tri-n-octylamine and Aliquat 336. J Chem Eng Data. 2016;61(9): 3217-3224.

22. Zhao Y, Liu S, Lu Z, Zhao B, Yu A. Hybrid promoter engineering strategies in Yarrowia lipolytica: isoamyl alcohol production as a test study. Biotechnol Biofuels. 2021;14(1). https://www.researchsquare.com/article/rs369447/v1

23. Zhang Y, Peng J, Zhao H, Shi S. Engineering oleaginous yeast Rhodosporidium Toruloides for overproduction of fatty acid ethyl esters. 2020. https://www.researchsquare.com/article/rs-131804/v1

24. Ye Z, Li S, Hennigan JN, Lebeau J, Lynch MD. Two-stage dynamic deregulation of metabolism improves process robustness \& scalability in engineered E. coli. 2020. https://www.biorxiv.org/content/10.1101/2020.08.30.274290v1

25. Atsumi S, Hanai T, Liao JC. Non-fermentative pathways for synthesis of branched-chain higher alcohols as biofuels. Nature. 2008;451(7174):86-89.

26. Jang WD, Kim GB, Kim Y, Sang YL. Applications of artificial intelligence to enzyme and pathway design for metabolic engineering. Curr Opin Biotechnol. 2022;73:101-107.

27. Xu P, Gu Q, Wang W, Wong L, Bower A, Collins CH, Koffas M. Modular optimization of multi-gene pathways for fatty acids production in E. coli. Nat Commun. 2013;4:1409.

28. Chen Z, Shen X, Jian W, Jia W, Yuan Q, Yan Y. Rational engineering of $p$-ydroxybenzoate hydroxylase to enable efficient gallic acid synthesis via a novel artificial biosynthetic pathway. Biotechnol Bioeng. 2017;114(11):25712580.

29. Huo YX, Ren H, Yu H, Zhao L, Yu S, Yan Y, Chen Z. CipA-mediating enzyme self-assembly to enhance the biosynthesis of pyrogallol in Escherichia coli. Appl Microbiol Biotechnol. 2018;102:10005-10015.

30. Eschrich, K., Bolt VD, F. JT, Kok D, A., Berkel V, W. JH. Role of Tyr201 and Tyr385 in substrate activation by $p$ hydroxybenzoate hydroxylase from Pseudomonas fluorescens. Eur J Biochem. 1993;216(1):137-146.

31. Entsch B, Palfey BA, Ballou DP, Massey V. Catalytic function of tyrosine residues in para-hydroxybenzoate hydroxylase as determined by the study of site-directed mutants. J Biol Chem. 1991;266(26):17341-17349.

32. Yu H, Chen Z, Wang N, Yu S, Huo YX. Engineering transcription factor BmoR for screening butanol overproducers. Metab Eng. 2019;56: 28-38.

33. Bailey RG, Nursten HE, Mcdowell I. The chemical oxidation of catechins and other phenolics: A study of the formation of black tea pigments. J Sci Food Agric. 2010;63(4):455-464.

34. Caregnato P, Gara PD, Bosio GN, Gonzalez MC, Russo N, Michelini M, Mártire D. Theoretical and experimental investigation on the oxidation of gallic acid by sulfate radical anions. J Phys Chem A. 2008;112(6):1188-1194.

35. Kamel MY, Saleh NA, Ghazy AM. Gallic acid oxidation by turnip peroxidase. Phytochemistry. 1977;16(5):521-524.

36. Melo RP, Leal JP, Botelho ML. Radiolytic degradation mechanism of gallic acid and its end-products. Rapid Commun Mass Spectrom. 2011;25(1):218-222.

37. Pospíšil F, Cvikrová M, Hrubcová M. Oxidation of gallic acid by an enzyme preparation isolated from the culture medium of Nicotiana tabacum cell suspension. Biol Plant. 1983;25(5):373-377.

38. Cole LJ, Entsch B, Ortizmaldonado M, Ballou DP. Properties of p-hydroxybenzoate hydroxylase when stabilized in its open conformation. Biochemistry. 2005;44(45):14807-14817.

39. Gatti DL, Entsch B, Ballou DP, Ludwig§ M. pH-dependent structural changes in the active site of $p$ hydroxybenzoate hydroxylase point to the importance of proton and water movements during catalysis. 
Biochemistry. 1996;35(2):567-578.

40. Broach JR, Hicks JB. Replication and recombination functions associated with the yeast plasmid, $2 \propto$ circle. Cell. 1980;21(2):501-508.

\section{Tables}


Table 1

Plasmids and strains used in this study

\begin{tabular}{|c|c|c|}
\hline $\begin{array}{l}\text { Plasmids } \\
\text { and strains }\end{array}$ & Description & Source \\
\hline \multicolumn{3}{|l|}{ Plasmids } \\
\hline pZE12-luc & $P_{L}$ lac01; colE1; $a m p^{r}$ & Storage \\
\hline pCS-PDC & $P_{L}$ lac01-PDC; P15A; kan ${ }^{r}$ & Storage \\
\hline pETDuet-1 & $P_{T 7} ; p B R 322 ; a m p^{r}$ & Storage \\
\hline pKD46 & $P_{\text {araB-gam-beta-exo; pCS101; amp }}{ }^{r}$ & Storage \\
\hline pCP20 & 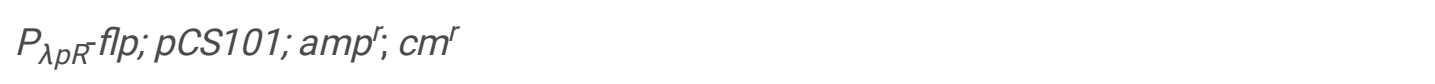 & Storage \\
\hline pZE-PobA ${ }^{* *}$ & $P_{L}$ lac01-Y385F/T294A PobA; colE1; ampr & $\begin{array}{l}\text { This } \\
\text { study }\end{array}$ \\
\hline pZE-PobA $A^{\star * \star}$ & $P_{L}$ lac01-Y385F/T294A/V349A PobA; colE1; amp ${ }^{r}$ & $\begin{array}{l}\text { This } \\
\text { study }\end{array}$ \\
\hline $\begin{array}{l}\text { pETDuet- } \\
\text { PobA }^{* \star}\end{array}$ & $P_{T T} Y 385 F / T 294 A$ PobA; pBR322; amp ${ }^{r}$ & $\begin{array}{l}\text { This } \\
\text { study }\end{array}$ \\
\hline $\begin{array}{l}\text { pETDuet- } \\
\text { PobA }^{* \star *}\end{array}$ & $P_{T T} Y 385 F / T 294 A / V 349 A$ PobA; pBR322; amp ${ }^{r}$ & $\begin{array}{l}\text { This } \\
\text { study }\end{array}$ \\
\hline pZE-AroZ & $P_{L}$ lac01-AroZ; colE1; amp ${ }^{r}$ & $\begin{array}{l}\text { This } \\
\text { study }\end{array}$ \\
\hline $\begin{array}{l}\text { pZE-AroZ- } \\
\text { PobA }^{* *}\end{array}$ & $P_{L}$ lac01-AroZ; $P_{L}$ lac01-Y385F/T294A PobA; colE1; amp ${ }^{r}$ & $\begin{array}{l}\text { This } \\
\text { study }\end{array}$ \\
\hline $\begin{array}{l}\text { pZE-AroZ- } \\
\text { PobA }^{\star \star *}\end{array}$ & $P_{L}$ lac01-AroZ; $P_{L}$ lac01-Y385F/T294A/V349A PobA; colE1; amp ${ }^{r}$ & $\begin{array}{l}\text { This } \\
\text { study }\end{array}$ \\
\hline \multicolumn{3}{|l|}{$\begin{array}{l}\text { E. coli } \\
\text { strains }\end{array}$} \\
\hline XL10-Gold & 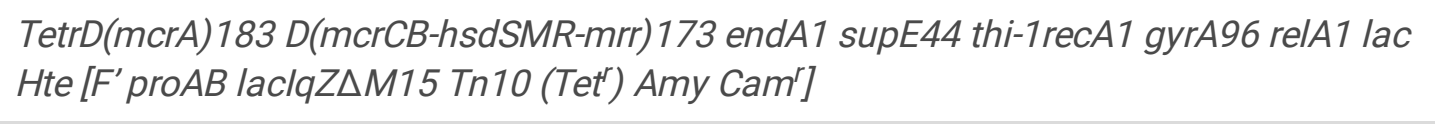 & Storage \\
\hline $\begin{array}{l}\text { BW25113 } \\
\left(F^{\prime}\right)\end{array}$ & 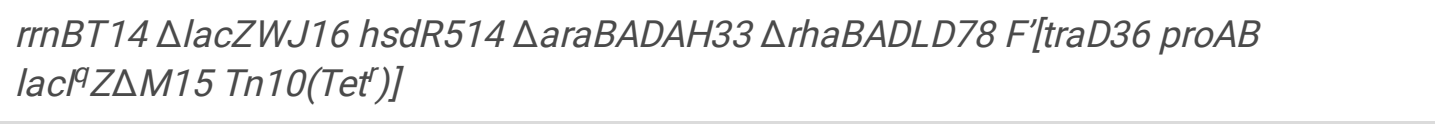 & Storage \\
\hline BL21(DE3) & $F^{-}$ompt hsdS (rB $\left.{ }^{-} m B^{-}\right) \mathrm{gal} d c m(D E 3)$ & Storage \\
\hline CTT1 & BW25113 (F') with pZE-PobA ${ }^{* *}$ & $\begin{array}{l}\text { This } \\
\text { study }\end{array}$ \\
\hline СТT2 & BW25113 (F') with pZE-PobA ${ }^{\star * *}$ & $\begin{array}{l}\text { This } \\
\text { study }\end{array}$ \\
\hline СTT3 & BW25113 (F') with pZE-PobA ${ }^{\star *}$ and pCS-PDC & $\begin{array}{l}\text { This } \\
\text { study }\end{array}$ \\
\hline
\end{tabular}




\begin{tabular}{|c|c|c|}
\hline $\begin{array}{l}\text { Plasmids } \\
\text { and strains }\end{array}$ & Description & Source \\
\hline CTT4 & BW25113 (F') with pZE-PobA ${ }^{\star \star \star}$ and pCS-PDC & $\begin{array}{l}\text { This } \\
\text { study }\end{array}$ \\
\hline CTT5 & BW25113 $\left(\mathrm{F}^{\prime}\right) \Delta a r o E$ & $\begin{array}{l}\text { This } \\
\text { study }\end{array}$ \\
\hline CTT6 & BW25113 $\left(\mathrm{F}^{\prime}\right) \Delta$ aroE $\Delta y d i B$ & $\begin{array}{l}\text { This } \\
\text { study }\end{array}$ \\
\hline CTT7 & BW25113 (F') with pZE-AroZ & $\begin{array}{l}\text { This } \\
\text { study }\end{array}$ \\
\hline СTT8 & CTT5 with pZE-AroZ & $\begin{array}{l}\text { This } \\
\text { study }\end{array}$ \\
\hline СTT9 & CTT6 with pZE-AroZ & $\begin{array}{l}\text { This } \\
\text { study }\end{array}$ \\
\hline CTT10 & BW25113 (F') with pZE-AroZ-PobA ${ }^{* *}$ & $\begin{array}{l}\text { This } \\
\text { study }\end{array}$ \\
\hline CTT11 & CTT5 with pZE-AroZ-PobA ${ }^{* *}$ & $\begin{array}{l}\text { This } \\
\text { study }\end{array}$ \\
\hline CTT12 & CTT6 with pZE-AroZ-PobA ${ }^{* *}$ & $\begin{array}{l}\text { This } \\
\text { study }\end{array}$ \\
\hline CTT13 & BW25113 (F') with pZE-AroZ-PobA ${ }^{* \star *}$ & $\begin{array}{l}\text { This } \\
\text { study }\end{array}$ \\
\hline CTT14 & CTT5 with pZE-AroZ-PobA ${ }^{* \star *}$ & $\begin{array}{l}\text { This } \\
\text { study }\end{array}$ \\
\hline CTT15 & CTT6 with pZE-AroZ-PobA ${ }^{\star \star *}$ & $\begin{array}{l}\text { This } \\
\text { study }\end{array}$ \\
\hline CTT16 & BW25113 (F') with pZE-AroZ-PobA ${ }^{* *}$ and pCS-PDC & $\begin{array}{l}\text { This } \\
\text { study }\end{array}$ \\
\hline CTT17 & CTT5 with pZE-AroZ-PobA ${ }^{\star *}$ and pCS-PDC & $\begin{array}{l}\text { This } \\
\text { study }\end{array}$ \\
\hline CTT18 & CTT6 with pZE-AroZ-PobA** and pCS-PDC & $\begin{array}{l}\text { This } \\
\text { study }\end{array}$ \\
\hline CTT19 & BW25113 (F') with pZE-AroZ-PobA ${ }^{\star \star \star}$ and pCS-PDC & $\begin{array}{l}\text { This } \\
\text { study }\end{array}$ \\
\hline СTT20 & CTT5 with pZE-AroZ-PobA ${ }^{\star \star \star}$ and pCS-PDC & $\begin{array}{l}\text { This } \\
\text { study }\end{array}$ \\
\hline СTT21 & CTT6 with pZE-AroZ-PobA* ${ }^{\star \star}$ and pCS-PDC & $\begin{array}{l}\text { This } \\
\text { study }\end{array}$ \\
\hline
\end{tabular}

Table 2 Kinetic parameters of PobA mutants towards 4-HBA and 3,4-DHBA 


\begin{tabular}{|c|c|c|c|c|c|c|c|c|c|}
\hline & \multirow[b]{2}{*}{ PobA mutants } & \multicolumn{4}{|l|}{ 4-HBA } & \multicolumn{4}{|c|}{ 3,4-DHBA } \\
\hline & & $\begin{array}{l}V_{\max } \\
\left(\mu \mathrm{M} \cdot \mathrm{s}^{-1}\right)\end{array}$ & $\begin{array}{l}K_{\mathrm{m}} \\
(\mu \mathrm{M})\end{array}$ & $\begin{array}{l}k_{\text {cat }} \\
\left(\mathrm{s}^{-1}\right)\end{array}$ & $\begin{array}{l}k_{\text {cat }} / K_{\mathrm{m}} \\
\left(\mu \mathrm{M}^{-1} \cdot \mathrm{s}^{-1}\right)\end{array}$ & $\begin{array}{l}V_{\max } \\
\left(\mu \mathrm{M} \cdot \mathrm{s}^{-1}\right)\end{array}$ & $\begin{array}{l}K_{\mathrm{m}} \\
(\mu \mathrm{M})\end{array}$ & $\begin{array}{l}k_{\text {cat }} \\
\left(\mathrm{s}^{-1}\right)\end{array}$ & $\begin{array}{l}k_{\mathrm{cat}} / K_{\mathrm{m}} \\
\left(\mu \mathrm{M}^{-1} \cdot \mathrm{s}^{-1}\right)\end{array}$ \\
\hline \multirow{3}{*}{$\begin{array}{l}\text { Chen } \\
\text { et al. } \\
\text { [28] }\end{array}$} & Wild type & $\begin{array}{l}0.35 \pm \\
0.04\end{array}$ & $\begin{array}{l}34.67 \\
\pm \\
9.51\end{array}$ & $\begin{array}{l}14.12 \\
\pm \\
1.49\end{array}$ & 0.41 & - & - & - & - \\
\hline & Y385F & $\begin{array}{l}0.20 \pm \\
0.001\end{array}$ & $\begin{array}{l}19.55 \\
\pm \\
0.32\end{array}$ & $\begin{array}{l}0.20 \\
\pm \\
0.001\end{array}$ & 0.01 & $\begin{array}{l}0.39 \pm \\
0.06\end{array}$ & $\begin{array}{l}228.02 \\
\pm \\
53.57\end{array}$ & $\begin{array}{l}0.39 \\
\pm \\
0.06\end{array}$ & 0.002 \\
\hline & Y385F/T294A & $\begin{array}{l}0.45 \pm \\
0.01\end{array}$ & $\begin{array}{l}48.38 \\
\pm \\
3.00\end{array}$ & $\begin{array}{l}0.90 \\
\pm \\
0.03\end{array}$ & 0.02 & $\begin{array}{l}0.84 \pm \\
0.09\end{array}$ & $\begin{array}{l}157.02 \\
\pm \\
31.41\end{array}$ & $\begin{array}{l}1.69 \\
\pm \\
0.18\end{array}$ & 0.012 \\
\hline \multirow[t]{2}{*}{$\begin{array}{l}\text { This } \\
\text { study }\end{array}$} & Y385F/T294A & $\begin{array}{l}0.800 \pm \\
0.020\end{array}$ & $\begin{array}{l}89.9 \\
\pm \\
11.2\end{array}$ & $\begin{array}{l}1.60 \\
\pm \\
0.05\end{array}$ & 0.018 & $\begin{array}{l}0.79 \pm \\
0.12\end{array}$ & $\begin{array}{l}128 \pm \\
52\end{array}$ & $\begin{array}{l}1.59 \\
\pm \\
0.32\end{array}$ & 0.012 \\
\hline & Y385F/T294A/V349A & $\begin{array}{l}0.680 \pm \\
0.020\end{array}$ & $\begin{array}{l}14.5 \\
\pm 2.5\end{array}$ & $\begin{array}{l}1.36 \\
\pm \\
0.04\end{array}$ & 0.094 & $\begin{array}{l}0.89 \pm \\
0.08\end{array}$ & $\begin{array}{l}30.3 \pm \\
10.4\end{array}$ & $\begin{array}{l}1.78 \\
\pm \\
0.16\end{array}$ & 0.059 \\
\hline
\end{tabular}

\section{Figures}



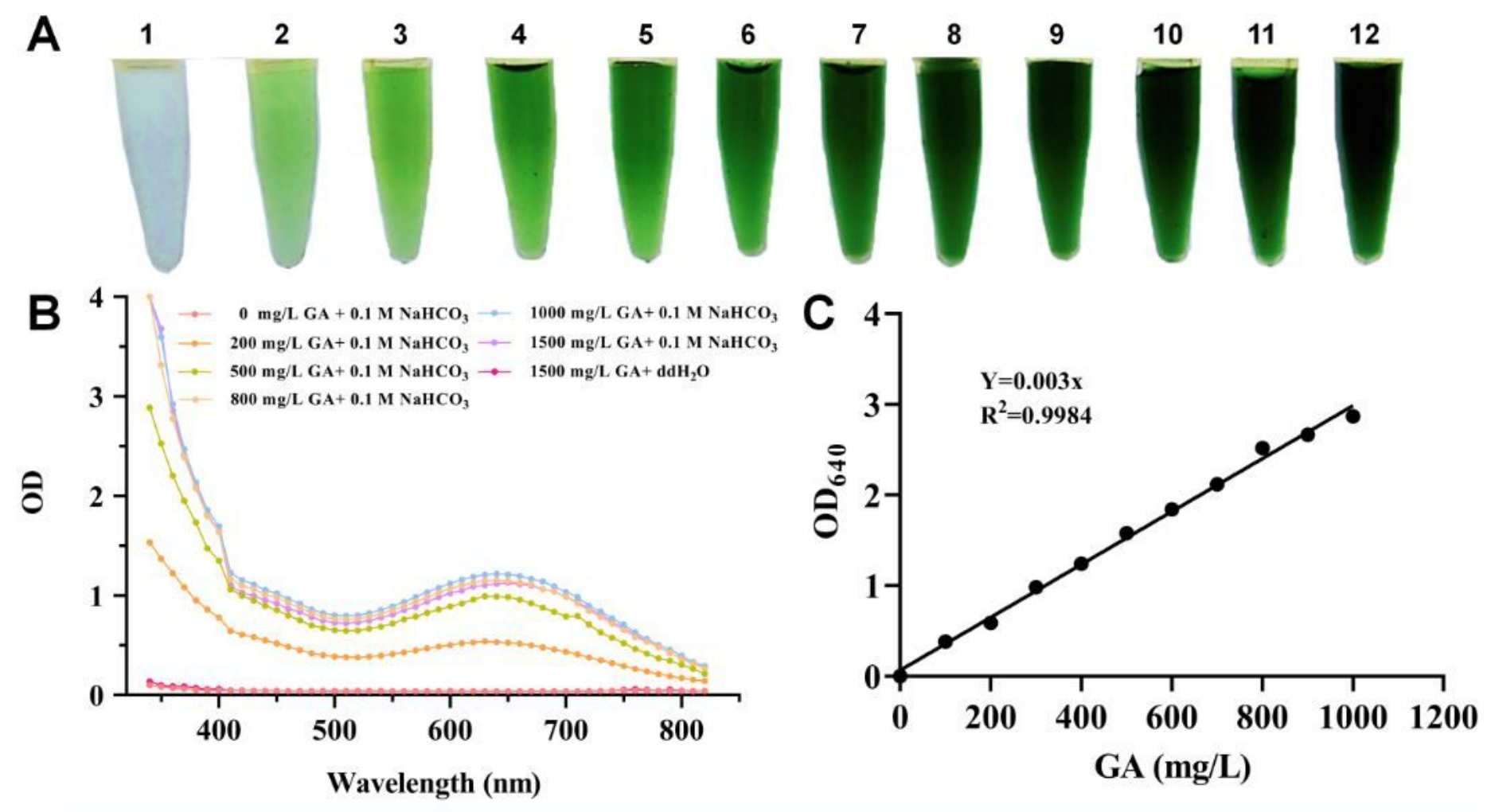

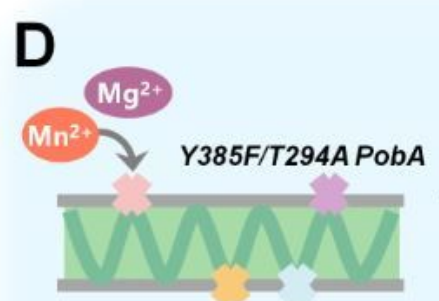

Error-prone PCR

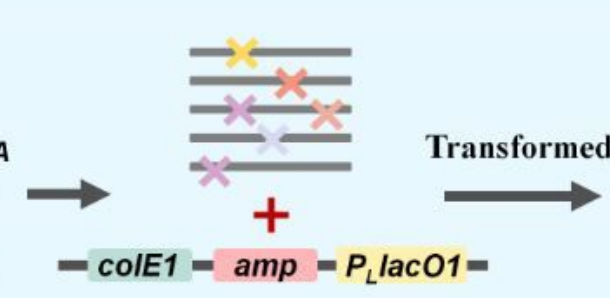

Gibson assembly
Mutagenesis library

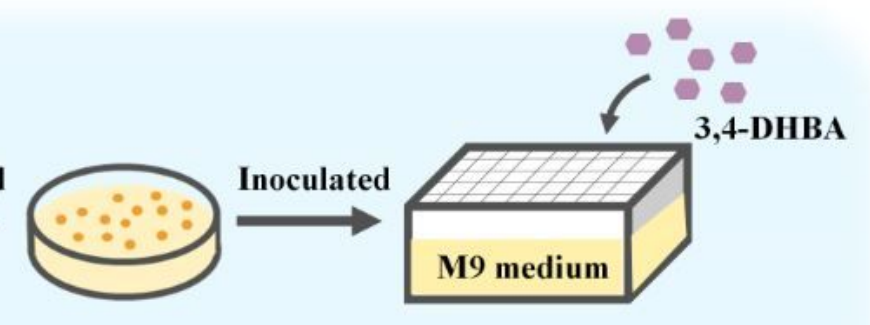

Feeding experiments

Took samples

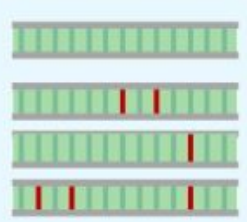

DNA sequencing

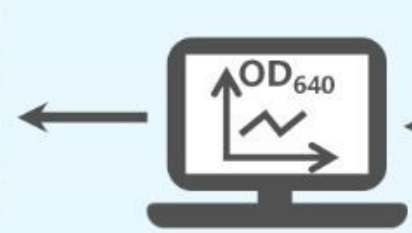

(1)

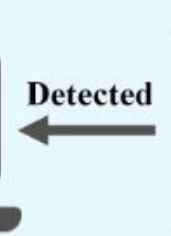

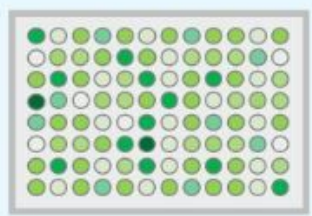

$30{ }^{\circ} \mathrm{C}, 2 \mathrm{~h}$

Figure 1

GA performance in alkaline conditions and the whole screening process of PobA mutants. $(A)$ The reaction mixture of GA and NaHCO3. GA concentrations in tube $1-12$ were $0,0.1,0.2,0.3,0.4,0.5,0.6,0.7,0.8,0.9,1.0,1.5 \mathrm{~g} / \mathrm{L}$, respectively. $\mathrm{NaHCO} 3$ concentration in the tube was $1 \mathrm{M}$. (B) The full wavelength (340-820 nm) scan results of the mixture. (C) The linear relationship of GA concentration and the optical density at $640 \mathrm{~nm}$. (D) The whole screening process for screening high active PobA mutants. 

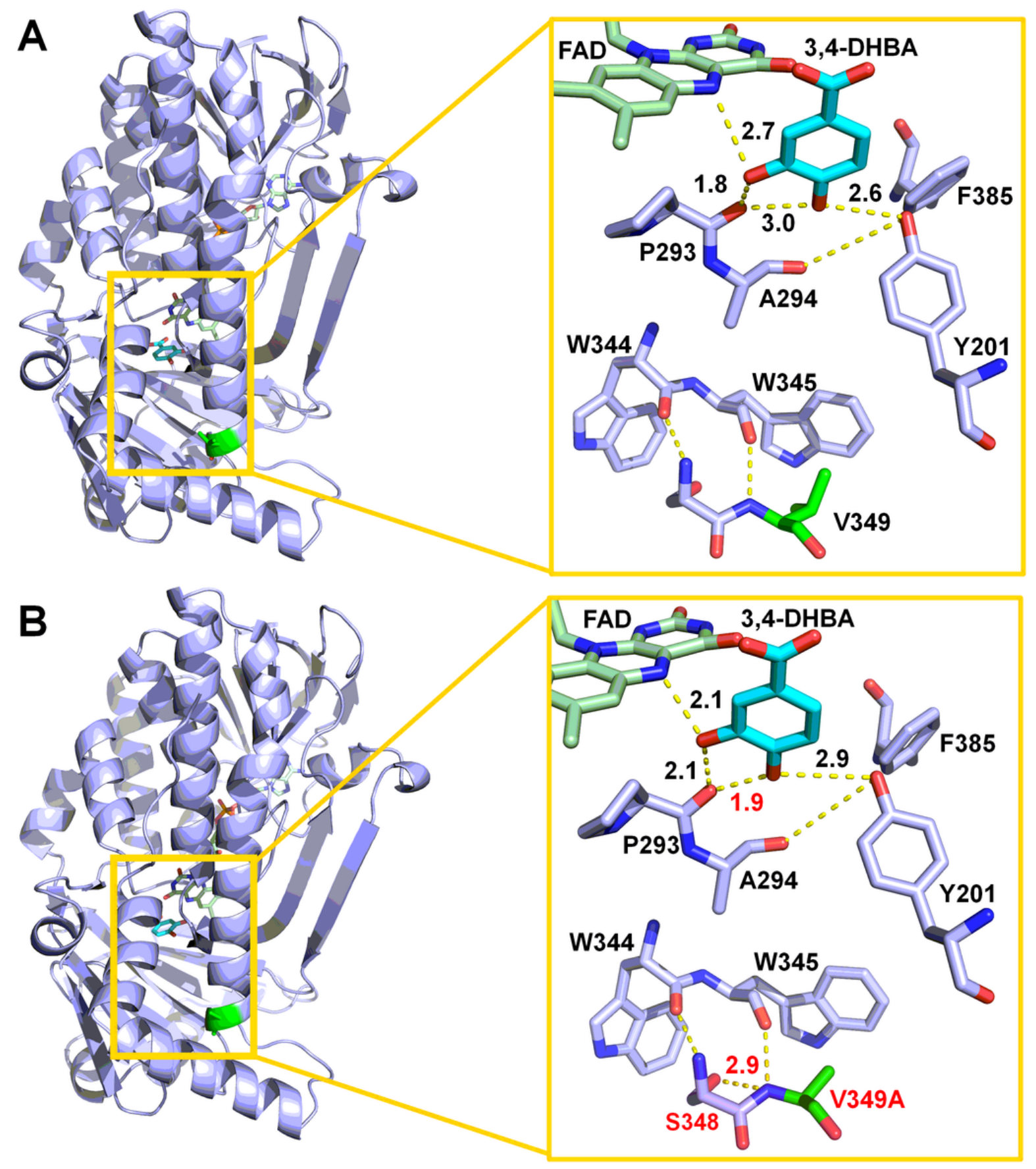

Figure 2

The catalytic pockets of PobA mutants. (A) Close view of the catalytic pocket of Y385F/T294A PobA with FAD and 3,4DHBA complex. (B) Close view of the catalytic pocket of Y385F/T294A/V349A PobA with FAD and 3,4-DHBA complex. The hydrogen bonds were shown as dashed line. 
A

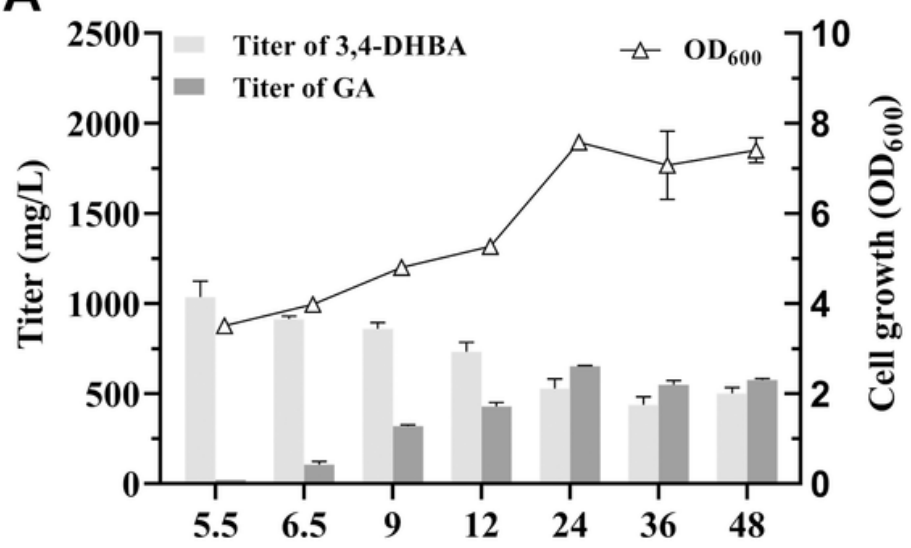

Time (h)

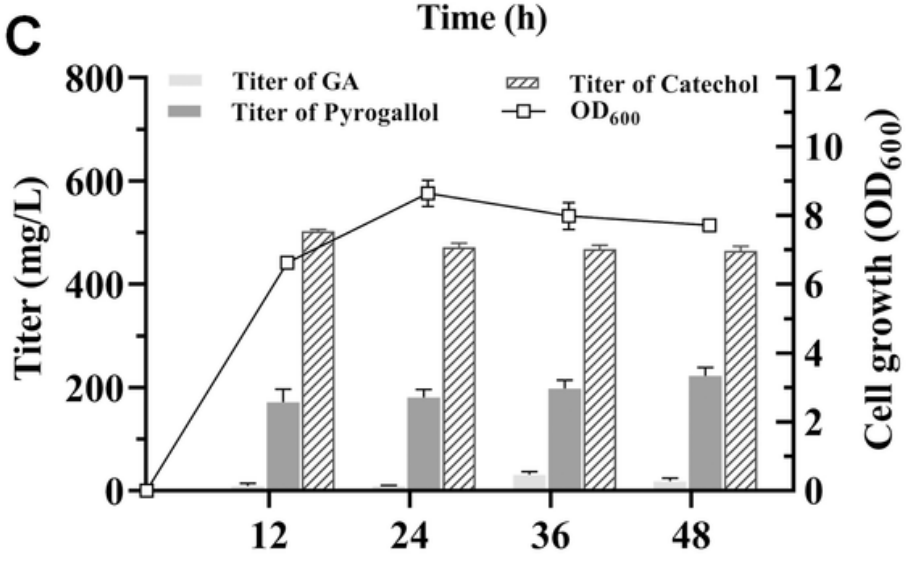

Time (h)
B

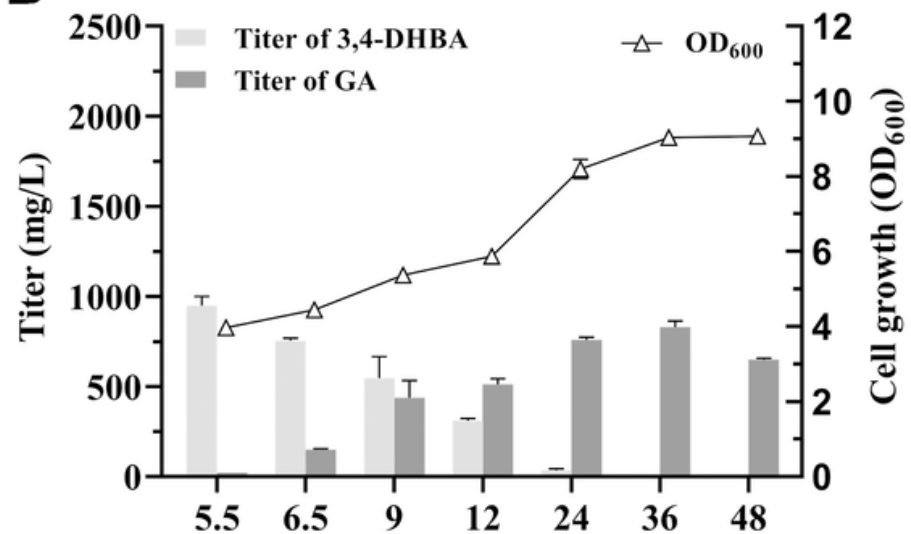

Time (h)

D

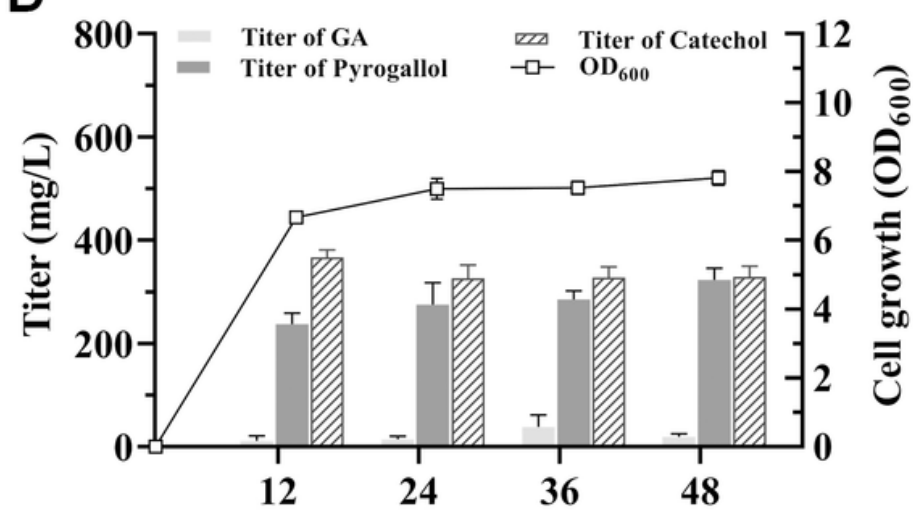

Time (h)

Figure 3

In vivo conversion of 3,4-DHBA into GA or pyrogallol. 3,4-DHBA with a concentration of $1000 \mathrm{mg} / \mathrm{L}$ was fed to the culture at 5.5 h. (A) Strain E. coli BW25113 (F') with pZE-PobA** (CTT1) was used. (B) Strain E. coli BW25113 (F') with

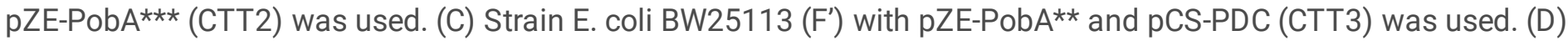

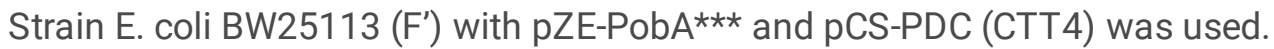




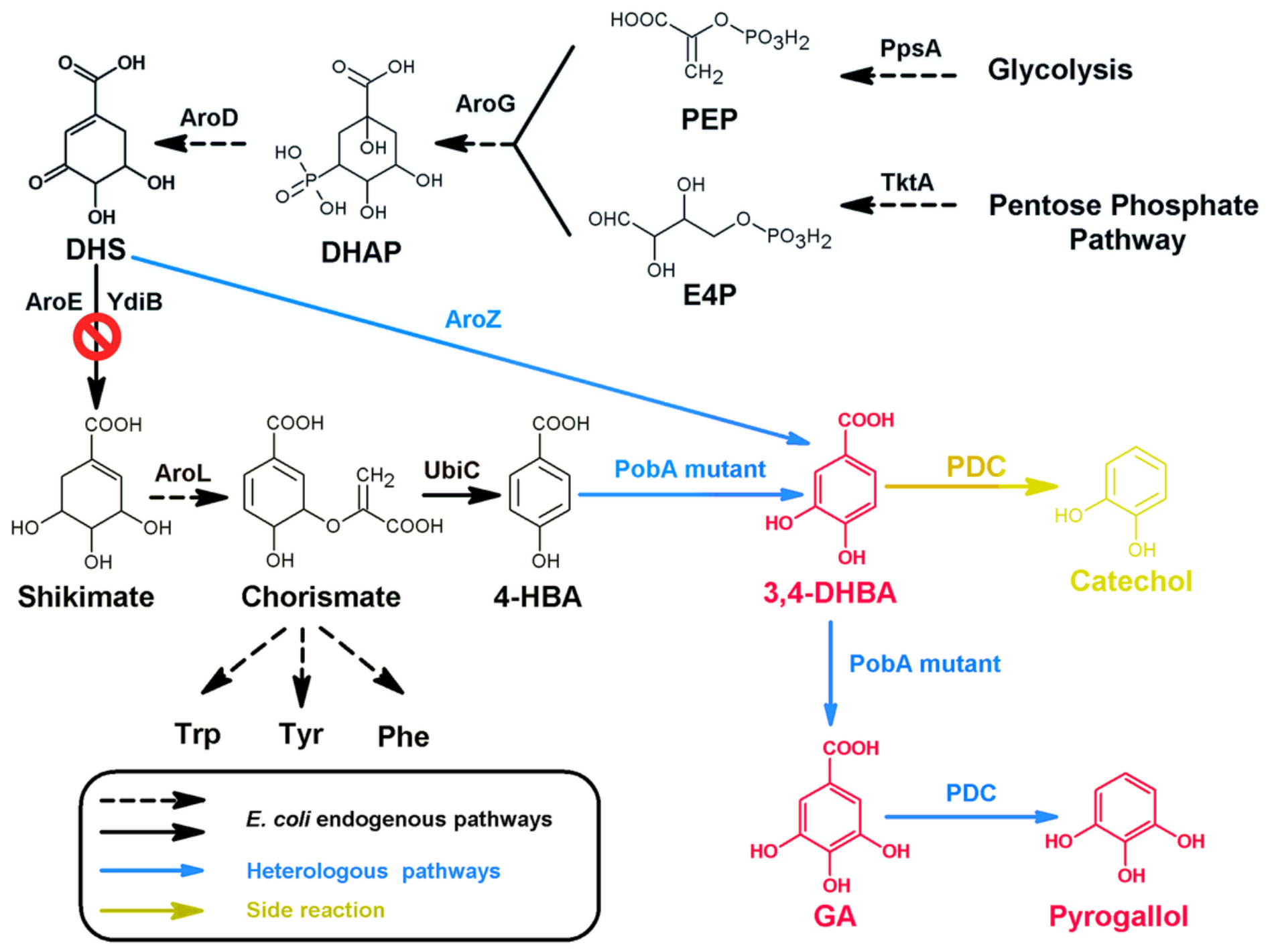

Figure 4

The de novo biosynthetic pathway of GA and pyrogallol. Black-colored arrows indicate the native pathways in E. coli; blue-colored arrow indicates the heterologous steps; yellow-colored arrow indicates side-reaction step. PEP, phosphoenolpyruvate; E4P , D-erythrose 4-phosphate; DAHP , 3-deoxy-D-arabinoheptulosonate 7-phosphate; DHS 3dehydroshikimate; 3,4-DHBA, 3,4-dihydroxybenzoic acid; GA, gallic acid; PpsA, phosphoenolpyruvate synthetase; TktA, transketolase; AroG, 2-dehydro-3-deoxyphosphoheptonate aldolase; AroD, 3-dehydroquinate dehydratase; AroE, shikimate dehydrogenase; YdiB, quinate/shikimate dehydrogenase; AroZ, 3-dehydroshikimate dehydratase; AroL, shikimate kinase II; UbiC, chorismate lyase; PobA mutant, p-hydroxybenzoate hydroxylase with mutations; PDC, 3,4dihydroxybenzoic acid decarboxylase. 

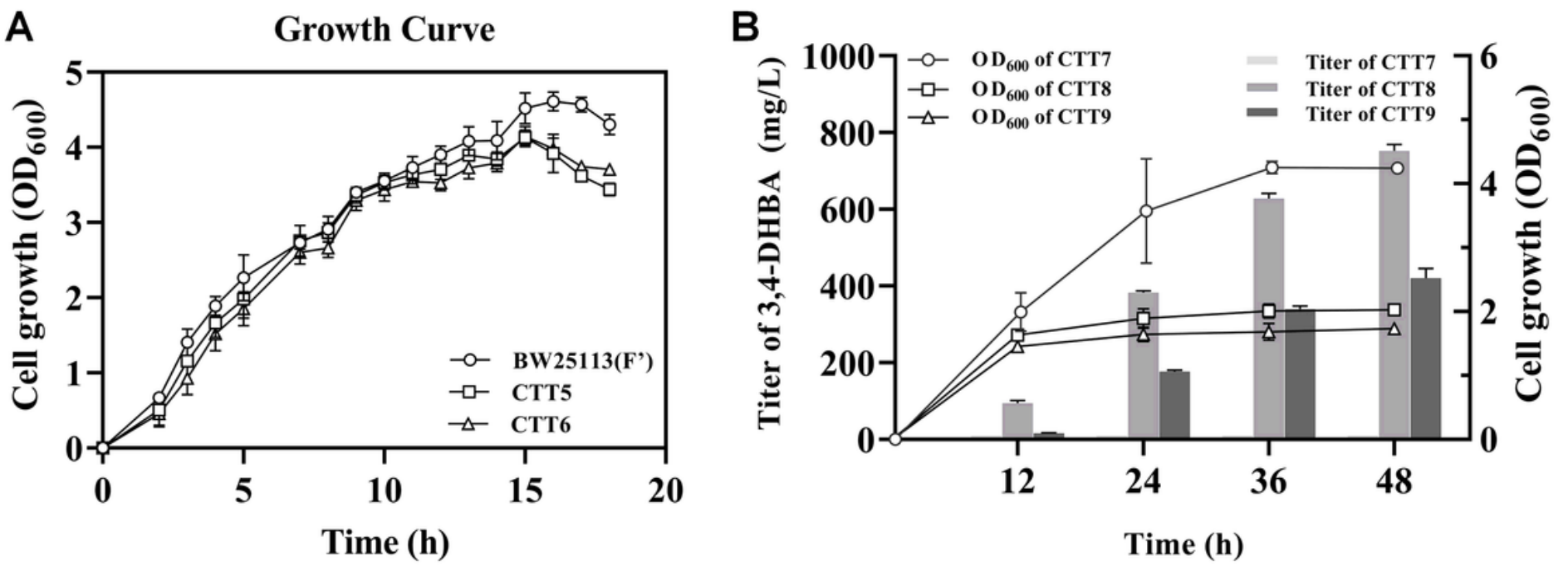

Figure 5

The cell growth and de novo production of 3,4-DHBA. (A) The growth curves of E. coli BW25113 (F'), E. coli BW25113 $\left(F^{\prime}\right) \triangle \operatorname{aroE}(C T T 5)$ and E. coli BW25113 $\left(F^{\prime}\right) \Delta \operatorname{aroE} \Delta y$ diB (CTT6) in LB medium. (B) 3,4-DHBA production of strains E. coli BW25113 (F') with pZE-AroZ (CTT7), CTT5 with pZE-AroZ (CTT8) and CTT6 with pZE-AroZ (CTT9) in M9Y medium.
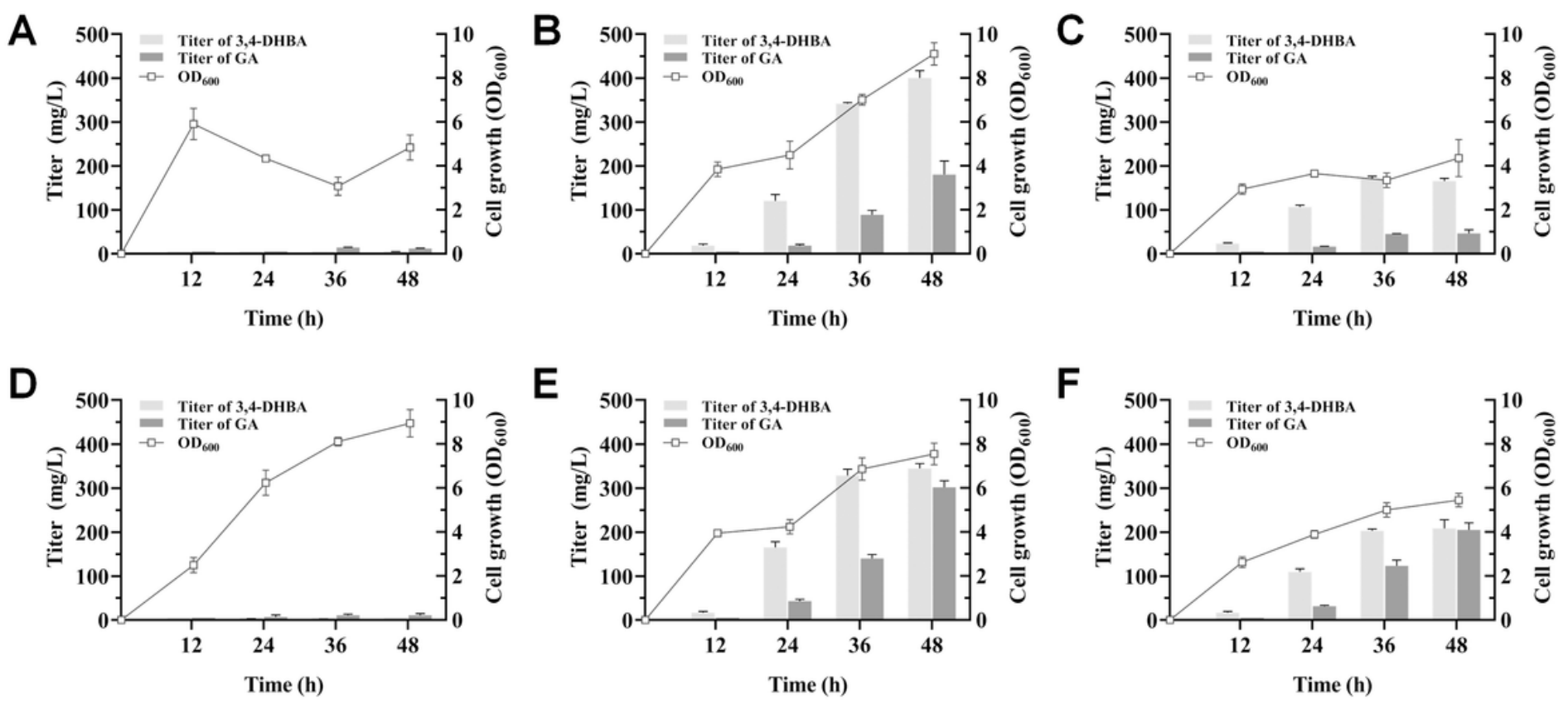

Figure 6

De novo production of GA. (A) Strain E. coli BW25113 (F') with pZE-AroZ-PobA** (CTT10) was used. (B) Strain CTT5 with pZE-AroZ-PobA** (CTT11) was used. (C) Strain CTT6 with pZE-AroZ-PobA** (CTT12) was used. (D) Strain E. coli BW25113 (F') with pZE-AroZ-PobA*** (CTT13) was used. (E) Strain CTT5 with pZE-AroZ-PobA*** (CTT14) was used. (F) Strain CTT6 with pZE-AroZ-PobA*** (CTT15) was used. 

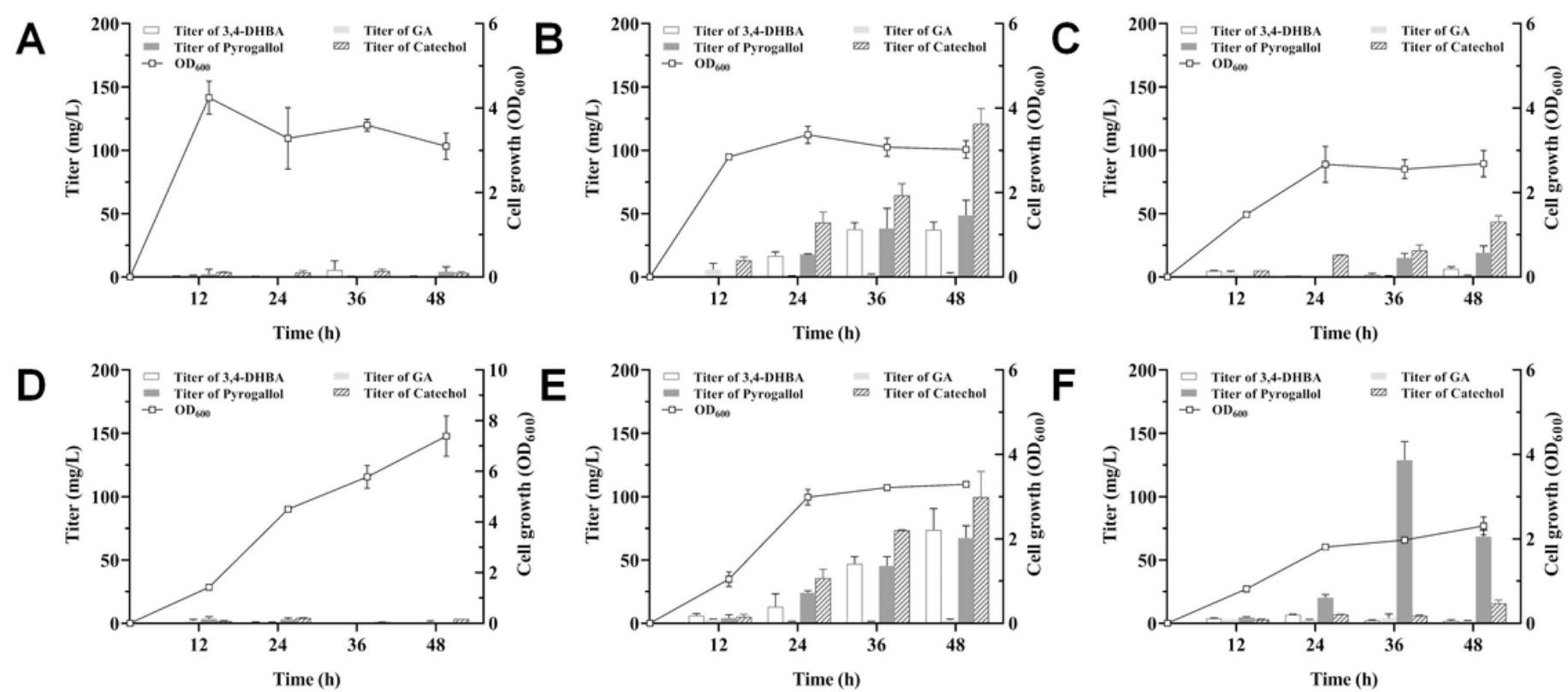

Figure 7

De novo production of pyrogallol. (A) Strain E. coli BW25113 (F') with pZE-AroZ-PobA** and pCS-PDC (CTT16) was used. (B) Strain CTT5 with pZE-AroZ-PobA** and pCS-PDC (CTT17) was used. (C) Strain CTT6 with pZE-AroZ-PobA** and pCS-PDC (CTT18) was used. (D) Strain E. coli BW25113 (F') with pZE-AroZ-PobA*** and pCS-PDC (CTT19) was used. (E) Strain CTT5 with pZE-AroZ-PobA*** and pCS-PDC (CTT20) was used. (F) Strain CTT6 with pZE-AroZ-PobA ${ }^{\star \star \star ~}$ and pCS-PDC (CTT21) was used.

\section{Supplementary Files}

This is a list of supplementary files associated with this preprint. Click to download.

- 20211020SupportingInformation.docx 